\title{
SINCRETISME I CANVI MORFOLÒGIC: EVOLUCIÓ DE LA TERMINACIÓ VERBAL EN -AT EN CATALÀ*
}

\author{
SYNCRETISM AND MORPHOLOGICAL CHANGE: \\ EVOLUTION OF THE VERBAL ENDING -AT IN CATALAN
}

\author{
Mar Massanell i Messalles \\ Universitat Autònoma de Barcelona \\ mar.massanell@uab.cat
}

Resum: La terminació verbal llatina -AT, que es troba en els ètims de les formes de za persona del present d'indicatiu de la ia conjugació, del present de subjuntiu de les conjugacions no primeres i de l'imperfet d'indicatiu i del condicional de totes les conjugacions, ha arribat en català general al resultat - $a$ (CANTAT > canta). Tanmateix, ja en els primers testimonis escrits (segle XI) procedents dels antics comtats d'Urgell i de Pallars, es documenta la variant $-e$, avui estesa pel català nord-occidental i pel valencià septentrional. Aquesta divergència ha rebut una explicació fonològica, a partir del supòsit que en el català occidental naixent la -T final s'hauria perdut de manera tardana, fet que hauria permès el tancament de A posttònica $(-\mathrm{AT}>-e t>-e)$. En aquest article, partint dels principis de la morfologia natural, plantegem una hipòtesi alternativa que atribueix el sorgiment i l'expansió de la variant $-e$ a factors morfològics com el rebuig del sincretisme. Les dades que ha aportat el buidatge del Corpus Informatitzat del Català Antic sembla que concorden amb la hipòtesi formulada, tot i que la migradesa de textos dels orígens aconsella de ser prudents en les conclusions.

Paraules clau: sincretisme, canvi lingüístic, morfologia natural, flexió verbal, català antic, català nord-occidental.

Abstract: The Latin verbal ending -AT, found in etymons of forms of the 3 rd person present indicative (Ist conjugation), present subjunctive $\left(2^{\text {nd }}\right.$ and $3^{\text {rd }}$ conjugations), imperfect indicative and

$\left.{ }^{*}\right)$ Aquest article ha estat possible gràcies als projectes del MINECO FFI2013-40579P i FFI20I4-56968-

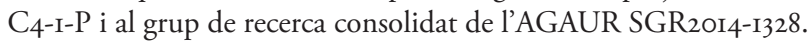


Mar Massanell i Messalles

Sincretisme i canvi morfològic: evolució de la terminació verbal en -AT en català

conditional (all conjugations), has generally become $-a$ (CANTAT > canta) in Catalan. However, variant $-e$, now found in Northwestern Catalan and in Northern Valencian, is already documented in the first written evidence from the old counties of Urgell and Pallars (IIth century). This divergence has received a phonological explanation, based on the assumption that in early Western Catalan final -T would have been lost late, which would have allowed the closure of the posttonic A $(-\mathrm{AT}>-e t>-e)$. Basing our argument on the principles of Natural Morphology, an alternative hypothesis is put forward in this paper, i.e. the emergence and expansion of variant $-e$ can be attributed to morphological factors such as the rejection of syncretism. The data collected from CICA (Computerised Corpus of Old Catalan) seem consistent with this hypothesis, although the paucity of early texts advises us to be cautious in our conclusions.

Key words: syncretism, linguistic change, Natural Morphology, verbal inflection, Old Catalan, Northwestern Catalan.

es es

vet regle general: que los vocables o mots se han scriure segons la primera, segona o terça persona, com ara: yo demane, yo camine; en la fi hi ha $e$, e no $a$; com hi haurà $a$, són en los altriess de terça persona, com ara: aquell camina, aquell demana

(Regles de esquivar vocables o mots grossers o pagesivols [324])

El català nord-occidental és un dialecte que defuig el sincretisme, és a dir, que evita atorgar més d'un valor gramatical a una mateixa forma lingüística. En concret, rebutja la coincidència formal entre la primera persona i la tercera en els paradigmes verbals. Es pot comprovar facilment repassant la flexió verbal nord-occidental i comparant-la, per exemple, amb la del català central. Mentre que en aquest només el present d'indicatiu i el futur tenen formes diferents per a les persones I i 3 (canto/ canta, cantarélcantarà), en nord-occidental tots els temps verbals practiquen aquesta distinció, inclosos l'imperfet d'indicatiu (jo cantava / ell cantave), el condicional (jo cantaria / ell cantarie), el present de subjuntiu (que jo canta / que ell canto) i l'imperfet de subjuntiu (que jo cantessa / que ell cantés). Les dades que donem com a exemple a la taula I (i, més endavant, a la 2) corresponen a la localitat d'Arbeca, a les Garrigues, però, pel que fa a aquest tret, són prou representatives de tot el dialecte, amb l'excepció de l'àrea subdialectal tortosina. ${ }^{1}$

I. Al llarg d'aquest article emprarem aquesta notació: ${ }_{3} \mathrm{PI}=$ tercera persona del singular del present d'indicatiu, $3 \mathrm{II}=$ tercera persona del singular de l'imperfet d'indicatiu, ${ }_{3} \mathrm{C}=$ tercera persona del singular del 
Taula I. Comparació de la flexió verbal del català central, amb diversos casos de sincretisme entre la primera persona i la tercera, i del nord-occidental, sense aquestes coincidències formals

\begin{tabular}{|c|c|c|c|c|c|c|}
\hline & $\begin{array}{c}\text { present } \\
\text { d'indicatiu }\end{array}$ & $\begin{array}{c}\text { imperfet } \\
\text { d'indicatiu }\end{array}$ & futur & condicional & $\begin{array}{c}\text { present } \\
\text { de subjuntiu }\end{array}$ & $\begin{array}{c}\text { imperfet } \\
\text { de subjuntiu }\end{array}$ \\
\hline central & \begin{tabular}{|l} 
canto \\
cantes \\
canta \\
cantem \\
canteu \\
canten \\
\end{tabular} & $\begin{array}{l}\text { cantava } \\
\text { cantaves } \\
\text { cantava } \\
\text { cantàvem } \\
\text { cantàveu } \\
\text { cantaven }\end{array}$ & $\begin{array}{l}\text { cantaré } \\
\text { cantaràs } \\
\text { cantarà } \\
\text { cantarem } \\
\text { cantareu } \\
\text { cantaran }\end{array}$ & $\begin{array}{l}\text { cantaria } \\
\text { cantaries } \\
\text { cantaria } \\
\text { cantariem } \\
\text { cantarieu } \\
\text { cantarien }\end{array}$ & \begin{tabular}{|l|} 
canti \\
cantis \\
canti \\
cantem \\
canteu \\
cantin \\
\end{tabular} & $\begin{array}{l}\text { cantés } \\
\text { cantessis } \\
\text { cantés } \\
\text { cantéssim } \\
\text { cantéssiu } \\
\text { cantessin }\end{array}$ \\
\hline $\begin{array}{c}\text { nord- } \\
\text { occidental }\end{array}$ & $\begin{array}{l}\text { canto } \\
\text { cantes } \\
\text { cante } \\
\text { cantem } \\
\text { canteu } \\
\text { canten }\end{array}$ & $\begin{array}{l}\text { cantava } \\
\text { cantaves } \\
\text { cantave } \\
\text { cantàvam } \\
\text { cantàvau } \\
\text { cantaven }\end{array}$ & $\begin{array}{l}\text { cantarè } \\
\text { cantaràs } \\
\text { cantarà } \\
\text { cantarem } \\
\text { cantareu } \\
\text { cantaran }\end{array}$ & $\begin{array}{l}\text { cantaria } \\
\text { cantaries } \\
\text { cantarie } \\
\text { cantariam } \\
\text { cantariau } \\
\text { cantarien }\end{array}$ & $\begin{array}{l}\text { canta } \\
\text { cantos } \\
\text { canto } \\
\text { cantem } \\
\text { canteu } \\
\text { canton }\end{array}$ & $\begin{array}{l}\text { cantessa } \\
\text { cantesses } \\
\text { cantés } \\
\text { cantéssam } \\
\text { cantéssau } \\
\text { cantessen }\end{array}$ \\
\hline
\end{tabular}

Aquesta tendència antisincrètica sembla ben afermada en el català nord-occidental actual, segons es desprèn d'alguns dels processos de canvi que viu aquest dialecte per la pressió de l'estàndard en modalitat central, que afecten —encara que de manera desigual — tot el territori, amb l'única excepció de l'Aragó catalanòfon (Massanell 20I2). Així, la penetració dels subjuntius centrals amb $i$, que provoca la substitució de cantesses per cantessis i, encara més, de cantos — connotat negativament- per cantis, ha suposat la generació d'un sistema de subjuntiu mixt, en què la primera persona, a diferència de les altres, sol mantenir la forma tradicional (que jo canta, que jo cantessa), per a preservar la distinció respecte de la tercera (Massanell \& Palà, en premsa), com es mostra a la taula 2.

condicional, ${ }_{3} \mathrm{PS}=$ tercera persona del singular del present de subjuntiu, ${ }_{3} \mathrm{PPI}=$ tercera persona del singular del plusquamperfet d'indicatiu (llatí), [Ia conj.] = primera conjugació, [-Ia conj.] = conjugacions no primeres; monstre 2 = dues ocurrències de la forma monstre. 
Taula 2. Comparació entre els temps de subjuntiu de l'estàndard central, difosos pels mitjans de comunicació i el sistema educatiu, i caracteritzats pel sincretisme entre la primera persona i la tercera, i els temps de subjuntiu nord-occidentals, sense sincretisme, tant el model tradicional com l'innovador, emprat sobretot per les capes de població més joves, i caracteritzat per l'adopció de les formes centrals, amb l'excepció de la primera persona, que es resisteix al canvi per a evitar la coincidència formal amb la tercera

\begin{tabular}{|c|c|c|c|}
\hline & $\begin{array}{l}\text { estàndard central } \\
\text { (model de pressió, } \\
\text { amb sincretisme } \\
\text { entre 1PS i 3PS) }\end{array}$ & $\begin{array}{l}\text { nord-occidental } 1 \\
\text { (model tradicional, } \\
\text { sense sincretisme } \\
\text { entre 1PS i 3PS) }\end{array}$ & $\begin{array}{c}\text { nord-occidental } 2 \\
\text { (model innovador mixt, } \\
\text { pres bàsicament del central però } \\
\text { sense sincretisme entre 1PS i 3PS) }\end{array}$ \\
\hline $\begin{array}{c}\text { present } \\
\text { de subjuntiu }\end{array}$ & $\begin{array}{l}\text { canti } \\
\text { cantis } \\
\text { canti } \\
\text { cantem } \\
\text { canteu } \\
\text { cantin }\end{array}$ & $\begin{array}{l}\text { canta } \\
\text { cantos } \\
\text { canto } \\
\text { cantem } \\
\text { canteu } \\
\text { canton }\end{array}$ & $\begin{array}{l}\text { canta } \\
\text { cantis } \\
\text { canti } \\
\text { cantem } \\
\text { canteu } \\
\text { cantin }\end{array}$ \\
\hline $\begin{array}{c}\text { imperfet } \\
\text { de subjuntiu }\end{array}$ & $\begin{array}{l}\text { cantés } \\
\text { cantessis } \\
\text { cantés } \\
\text { cantéssim } \\
\text { cantéssiu } \\
\text { cantessin }\end{array}$ & $\begin{array}{l}\text { cantessa } \\
\text { cantesses } \\
\text { cantés } \\
\text { cantéssam } \\
\text { cantéssau } \\
\text { cantessen }\end{array}$ & $\begin{array}{l}\text { cantessa } \\
\text { cantessis } \\
\text { cantés } \\
\text { cantéssim } \\
\text { cantéssiu } \\
\text { cantessin }\end{array}$ \\
\hline
\end{tabular}

Aquesta tendència antisincrètica que opera avui en el canvi dels subjuntius nord-occidentals és la mateixa que pensem que va intervenir en la formació i en l'expansió de la terminació -e de la tercera persona del present d'indicatiu de la primera conjugació (ell cante) i de l'imperfet d'indicatiu (ell cantave, ell batie) i del condicional (ell cantarie, ell batrie) de totes les conjugacions, que en l'actualitat s'estén pel nord-occidental, ${ }^{2}$ amb la sola excepció del tortosí estricte (comarques del Baix Ebre i el Montsià), i per una àmplia zona al nord del País Valencià, que abraça quasi completament el valencià septentrional (Veny \& Massanell 2015: 249, 265, 289). El sorgiment, a partir de formes llatines acabades en -AT (CANTAT '[ell] canta', CANTABAT '[ell] cantava'), d'aquestes formes catalanes amb - e final, que s'ha dit que són antigues com la mateixa llengua — tot i que, si volem ser precisos, només podem dir que són

2. En certa manera també es pot considerar que es troba, tancada en [i], en el parlar xipella, inclòs en el català central però ubicat a la divisòria amb el nord-occidental. Aquestes formes de tercera persona s'hi pronuncien amb [i] final: per exemple, ell cantav [i] en contrast amb jo cantav[a]. Aital realització només es pot haver generat a partir d'un estadi previ amb [e] a la terminació de tercera persona, atès que és la [e] del català preliterari la que va esdevenir-hi [i] en posició final lliure o travada (quinz[i], vaqu[i]s), però no pas la [a], la qual ha desembocat en [ə] (cas[ə]) com és general en el català central (Veny I998: 38). 
presents, al costat de les formes amb - $a$, des dels primers documents que conservem escrits parcialment o totalment en català-, planteja alguns interrogants al voltant dels quals hem bastit la reflexió continguda en aquest article. Som del parer, expressat per Martí i Castell (20I4: 9I), que «els processos lingüístics actuals són els mateixos que els que han operat històricament. És gràcies a les dades d'avui que es pot interpretar millor la història i no a l'inrevés".

\section{LA TERMINACIÓ VERBAL ÀTONA EN -AT: PRESÈNCIA EN ELS PARADIGMES VERBALS LLATINS}

En els paradigmes verbals llatins que són a l'origen de la conjugació verbal catalana (vegeu la taula 3), la terminació àtona -AT de tercera persona es trobava en el present d'indicatiu dels verbs de la primera conjugació (CANTAT '[ell] canta'), en el present de subjuntiu dels verbs de les conjugacions no primeres (BATTAT '[que ell] bati') i en l'imperfet d'indicatiu de totes les conjugacions (CANTABAT '[ell] cantava', BATTEBAT '[ell] batia'). També ocorria en el plusquamperfet d'indicatiu llatí (CANTAVERAT $>$ *CANTARAT $>$ cantara), que va prendre en llatí tardà un valor de condicional, observable encara en textos catalans antics, o de plusquamperfet de subjuntiu, mudat en català en imperfet de subjuntiu, valor amb el qual perviu en valencià, però no pas en nord-occidental, si deixem al marge la comarca de transició del Matarranya. ${ }^{3}$ A més, la creació per procediments perifràstics del condicional va generar una nova forma de tercera persona acabada en -AT, que afecta totes les conjugacions, i que va néixer a partir de l'erosió d'una perífrasi integrada per l'infinitiu del verb principal seguit de l'auxiliar HABEO conjugat en imperfet d'indicatiu (HABEBAT '[ell] havia'). 
Mar Massanell i Messalles

Sincretisme i canvi morfològic: evolució de la terminació verbal en -AT en català

Taula 3. Paradigmes verbals llatins del present d'indicatiu (PI), del present de subjuntiu (PS), de l'imperfet d'indicatiu (II), del plusquamperfet d'indicatiu (PPI) i del condicional (C) corresponents a un verb model de la primera conjugació (CANTO 'cantar') i a un verb model d'una de les conjugacions no primeres (BATTUO 'batre'). S'hi observa la terminació en -AT a la tercera persona del PI de la primera conjugació, del PS de les conjugacions no primeres i de l'II, el PPI i el C de totes les conjugacions

\begin{tabular}{|l|l|l|l|l|}
\hline $\begin{array}{c}\text { present } \\
\text { d'indicatiu }\end{array}$ & \multicolumn{1}{|c|}{$\begin{array}{c}\text { present } \\
\text { de subjuntiu }\end{array}$} & \multicolumn{1}{c|}{$\begin{array}{c}\text { imperfet } \\
\text { d'indicatiu }\end{array}$} & \multicolumn{1}{|c|}{$\begin{array}{c}\text { plusquamperfet } \\
\text { d'indicatiu }\end{array}$} & \multicolumn{1}{|c|}{ condicional } \\
\hline CÁNT-O & CÁNT-E-M & CANTÁ-BA-M & CANTÁ(V)-(E)RA-M & CANTÁR(E) (HAB)É-BA-M \\
CÁNTA-S & CÁNT-E-S & CANTÁ-BA-S & CANTÁ(V)-(E)RA-S & CANTÁR(E) (HAB)É-BA-S \\
CÁNTA-T & CÁNT-E-T & CANTÁ-BA-T & CANTÁ(V)-(E)RA-T & CANTÁR(E) (HAB)É-BA-T \\
CANTÁ-MUS & CANT-É-MUS & CANTA-BÁ-MUS & CANTA(V)-(E)RÁ-MUS & CANTÁR(E) (HAB)E-BÁ-MUS \\
CANTÁ-TIS & CANT-É-TIS & CANTA-BÁ-TIS & CANTA(V)-(E)RÁ-TIS & CANTÁR(E) (HAB)E-BÁ-TIS \\
CÁNTA-NT & CÁNT-E-NT & CANTÁ-BA-NT & CANTÁ(V)-(E)RA-NT & CANTÁR(E) (HAB)É-BA-NT \\
\hline BÁTT(U)-O & BÁTT-A-M & BATTÉ-BA-M & BATT(Ú)-ERA-M & BATT(Ú)ER(E) (HAB)É-BA-M \\
BÁTTI-S & BÁTT-A-S & BATTÉ-BA-S & BATT(Ú)-ERA-S & BATT(Ú)ER(E) (HAB)É-BA-S \\
BÁTTI-T & BÁTT-A-T & BATTÉ-BA-T & BATT(Ú)-ERA-T & BATT(Ú)ER(E) (HAB)É-BA-T \\
BATTÍ-MUS & BATT-Á-MUS & BATTE-BÁ-MUS & BATT(U)-ERÁ-MUS & BATT(Ú)ER(E) (HAB)E-BÁ-MUS \\
BATTÍ-TIS & BATT-Á-TIS & BATTE-BÁ-TIS & BATT(U)-ERÁ-TIS & BATT(Ú)ER(E) (HAB)E-BÁ-TIS \\
BÁTTU-NT & BÁTT-A-NT & BATTÉ-BA-NT & BATT(Ú)-ERA-NT & BATT(Ú)ER(E) (HAB)É-BA-NT \\
\hline
\end{tabular}

\section{LA CREACIÓ DE LES FORMES VERBALS CATALANES A PARTIR DE LES LLATINES}

Les formes verbals catalanes més antigues s'han d'explicar a partir de l'evolució fonètica de les llatines. Sovint, però, en el transcurs del temps s'han vist sotmeses a transformacions per factors que van més enllà de la fonètica i que entren de ple en el terreny de la morfologia, a causa del fet que les formes verbals estan inscrites en paradigmes, els quals posen sota pressió les formes que hi encaixen amb més dificultats. Tradicionalment s'esmenta l'analogia, fruit de la pruija regularitzadora, com a motor d'aquests canvis: «La morfologia verbal, tant en allò que afecta el radical com pel que fa a les desinències, respon fonamentalment a les lleis de l'evolució fonètica de l'idioma; secundàriament, però, està sotmesa a l'analogia en un grau tal que en molts casos anul.la la normalitat fonètica i dóna lloc a un gran volum d'excepcions, de tal manera que freqüentment resulta «regular» allò que és analògic i «irregular» allò que és fonètic» (Moll I991: I44).

$\mathrm{Val}$ a dir que les modificacions que els paradigmes poden provocar en les formes que els integren responen a mecanismes complexos quel'anomenada morfologia natural ${ }^{4}$

4. Els plantejaments teòrics de la morfologia natural es poden trobar a Dressler, Mayerthaler et alii i987; Wurzel 1989; Wheeler i993a. 
ha recollit en forma de principis, com el principi de transparència, el d'uniformitat, el d'iconicitat construccional i el de congruència del sistema (Pérez Saldanya I998: I3-33). Justament, el principi de transparència, que afavoreix els paradigmes sense ambigüitats, en els quals cada forma representa un únic valor gramatical, explica el rebuig al sincretisme i ha de tenir una gran importància en el dialecte nord-occidental, si hem de jutjar pels paradigmes que hem reproduït en la taula I.

\section{I. L'EVOLUCIÓ FONÈTICA I L'EXPANSIÓ DEL SINCRETISME}

Per evolució fonètica, les formes verbals catalanes més antigues corresponents als paradigmes que analitzem en aquest article són les que es recullen en la taula $4:^{5}$

Taula 4. Paradigmes verbals catalans originaris del present d'indicatiu, del present de subjuntiu, de l'imperfet d'indicatiu, de l'imperfet de subjuntiu amb ròtica (mantingut en valencià i que antigament també tenia valor condicional) i del condicional corresponents a un verb model de la primera conjugació (cantar) i a un verb model d'una conjugació no primera (batre); s'hi veu com els casos de sincretisme de persona hi eren nombrosos

\begin{tabular}{|c|c|c|c|c|}
\hline $\begin{array}{c}\text { present } \\
\text { d'indicatiu }\end{array}$ & $\begin{array}{c}\text { present } \\
\text { de subjuntiu }\end{array}$ & $\begin{array}{c}\text { imperfet } \\
\text { d'indicatiu }\end{array}$ & $\begin{array}{l}\text { imperfet de subjuntiu } \\
\text { (i ant. condicional) }\end{array}$ & condicional \\
\hline $\begin{array}{l}\text { cant } \\
\text { cantes } \\
\text { canta } \\
\text { cantam } \\
\text { cantats }>\text { cantau } \\
\text { canten }\end{array}$ & $\begin{array}{l}\text { cant } \\
\text { cants } \\
\text { cant } \\
\text { cantem } \\
\text { cantets }>\text { canteu } \\
\text { canten }\end{array}$ & $\begin{array}{l}\text { cantava } \\
\text { cantaves } \\
\text { cantava } \\
\text { cantàvem } \\
\text { cantàvets > cantàveu } \\
\text { cantaven }\end{array}$ & $\begin{array}{l}\text { cantara } \\
\text { cantares } \\
\text { cantara } \\
\text { cantàrem } \\
\text { cantàrets > cantàreu } \\
\text { cantaren }\end{array}$ & $\begin{array}{l}\text { cantaria } \\
\text { cantaries } \\
\text { cantaria } \\
\text { cantariem } \\
\text { cantariets > cantarieu } \\
\text { cantarien }\end{array}$ \\
\hline $\begin{array}{l}\text { bat } \\
\text { bats } \\
\text { bat } \\
\text { batem } \\
\text { batets > bateu } \\
\text { baten }\end{array}$ & $\begin{array}{l}\text { bata } \\
\text { bates } \\
\text { bata } \\
\text { batam } \\
\text { batats > batau } \\
\text { baten }\end{array}$ & \begin{tabular}{|l|} 
batia \\
baties \\
batia \\
batiem \\
batiets > batieu \\
batien \\
\end{tabular} & $\begin{array}{l}\text { batera } \\
\text { bateres } \\
\text { batera } \\
\text { batérem } \\
\text { batérets > batéreu } \\
\text { bateren }\end{array}$ & $\begin{array}{l}\text { batria } \\
\text { batries } \\
\text { batria } \\
\text { batriem } \\
\text { batriets > batrieu } \\
\text { batrien }\end{array}$ \\
\hline
\end{tabular}

La fesomia que presenten respon a canvis fonètics ben coneguts del llatí vulgar i del català preliterari. Entre els primers, podem esmentar la pèrdua de la -M en posició final (BATTAM > [bátta]), l'obertura de les vocals breus (BATTǏs $>$ [báttes], CANTAMǓS >

5. Partim de formes amb - $a$ final a la tercera persona, que són les del català general. Pensem que també eren, inicialment, les del nord-occidental, com intentarem de justificar al llarg d'aquest article. 
[kantámos]) i la lenició de les obstruents intervocàliques (BATTEBATIS $>$ [batévades]). ${ }^{6}$ Entre els segons, s'hi compten la pèrdua de les vocals àtones finals diferents de - $a$ (BATTǏs $>[$ bátes] $>$ [bats], però BATTUNT $>$ [báton] $>$ [báten], amb vocal de suport), el tancament de $-a$ final en síl.laba travada (CANTAS $>$ [kántes], CANTANT $>$ [kánten]) — sobre el qual tornarem més endavant- i la semivocalització d'aproximants implosives $($ CANTATIS $>[$ kantádes $]>[$ kantádz $]>[$ kantád $]>[$ kantáw $]$ ).

Molts d'aquests processos d'evolució fonètica s'inscriuen en una de les grans tendències evolutives que va afectar el llatí vulgar: l'erosió de les terminacions, per pèrdua de tensió articulatòria a final de mot (Väänänen 1985). Aquesta erosió va afectar, tot i que en períodes diferents i amb una extensió geogràfica també diversa, tant les consonants com les vocals. És molt primerenca i generalitzada la pèrdua de la $-\mathrm{M}$ final, que justifica, per exemple, el pas de CANTABAM a cantava. És molt més tardana i limitada, en canvi, l'apòcope de vocals finals diferents de A, que explica, posem per cas, el pas de CANTO a cant $\mathrm{o}$, juntament amb la llei anterior, la seqüència CANTEM > CANTE $>$ cant. Totes aquestes transformacions atacaven directament les marques de persona de les formes verbals, ubicades en darrer terme: $-\mathrm{M}$ (-O en el present d'indicatiu), -S, -T, -MUS, -TIS, -NT, gràcies a les quals no hi havia en llatí casos de sincretisme de persona en els temps que s'analitzen.

En català, en canvi, el sincretisme va proliferar: a la primera conjugació, la primera persona i la tercera coincidien en el present de subjuntiu (que jo cant, que ell cant), en l'imperfet d'indicatiu (jo cantava, ell cantava), en el condicional (jo cantaria, ell cantaria) i en l'antic plusquamperfet d'indicatiu (que jo cantara, que ell cantara); se'n salvava, en canvi, el present d'indicatiu (jo cant, ell canta). En les conjugacions no primeres, la coincidència formal entre la primera persona i la tercera tenia encara més abast i afectava el present d'indicatiu (jo bat, ell bat), el present de subjuntiu (que jo bata, que ell bata), l'imperfet d'indicatiu (jo batia, ell batia), el condicional (jo batria, ell batria) i l'imperfet de subjuntiu amb ròtica (que jo batera, que ell batera). ${ }^{7}$ Deixant de banda el present d'indicatiu —el temps menys marcat—, que avui distingeix la

6. Ultra aquests processos de fonètica regular, les formes catalanes resultants no es podrien explicar sense recórrer a la síncope vocàlica i consonàntica que va afectar les formes llatines més llargues (CANTAVERAM > * CANTARAm > cantara). Tampoc sense considerar els desplaçaments accentuals (CANTABámus, CANTABÁtis, però cantàvem, cantàveu), que només reben una explicació satisfactòria si es recorre a la pressió intraparadigmàtica.

7. El sincretisme no acabava aquí. Més enllà de la categoria de persona, també afectava la de mode (canten i baten podien ser sisena persona del present d'indicatiu o del present de subjuntiu; cant podia ser primera persona del present d'indicatiu o bé primera o tercera persona del present de subjuntiu). D'altra banda, s'hi violentava el principi d'uniformitat, que tendeix a evitar les variants al-lomòrfiques, atès que en les persones quarta i cinquena el present d'indicatiu es marcava amb la vocal /á/ en la primera conjugació (cantam, cantau) $\mathrm{i}$ amb la vocal /é/ en les conjugacions no primeres (batem, bateu), alhora que el present de subjuntiu presentava 
primera persona i la tercera a quasi tots els dialectes catalans, ${ }^{8}$ la resta de temps verbals mantenen majoritàriament la situació inicial de sincretisme, sigui amb les formes que ja hem vist (cantava, cantaria, val. cantara, val. que bata), sigui amb formes més modernes (que canti). El català nord-occidental no tortosí i el valencià septentrional, en canvi, no presenten cap d'aquests casos de sincretisme, sovint pel fet que la tercera persona es realitza amb [e] final (jo cantava, ell cantav[e]; jo cantaria, ell cantari[e]). D'on surt, però, aquesta [e]?

\section{I.I. La pèrdua de la -T final llatina i el tancament de la -A final en síl.laba travada}

La ubicació en el temps de les lleis d'evolució fonètica és un dels aspectes fonamentals —i més dificultosos — en la construcció d'una gramàtica històrica. Sovint esdevé un procés ple d'incerteses, especialment com més reculada sigui l'època que estudiem. Malgrat això, és clau saber en quin ordre han actuat les lleis d'evolució fonètica, i no costa gaire de constatar que dues lleis determinades, $a$ i $b$, no haurien donat els mateixos resultats evolutius aplicades en l'ordre invers, $b$ i $a$.

Dos processos que poden presentar interaccions, i que proporcionen resultats diferents segons l'ordre en què s'apliquin, són la pèrdua de la -T final llatina $(\mathrm{ET}>e) \mathrm{i}$ el tancament de la A àtona final en posició travada (ROSAS > roses). Observem que les formes verbals amb la terminació - AT poden complir les condicions perquè hi actuïn totes dues lleis, però l'ordenació hi és clau. Si es produeix primer la pèrdua de la dental (CANTAT > canta), la - $a$ deixa d'estar en síl-laba travada i no pateix el tancament en $e$ : el resultat final, doncs, és canta. En canvi, si actua primer el tancament vocàlic (CANTAT > cantet) i després es produeix la pèrdua de la dental (cantet $>$ cante), el resultat final és cante. Es pot pensar, per tant, que la doble solució catalana ell canta / ell cante, que constatem avui sincrònicament i que ja aflora en els primers textos conservats, té l'origen en una diferència en l'ordenació de les regles de pèrdua de la -T final llatina i de tancament de la A final travada: el català occidental naixent hauria perdut la dental més tardanament que el català oriental, raó per la qual s'hauria operat el tancament

una inversió de la situació i es marcava amb la vocal /él en la primera conjugació (que cantem, que canteu) i amb la vocal /ál en les conjugacions no primeres (que batam, que batau).

8. Central jo canto, ell canta; nord-occidental jo canto, ell cante; septentrional jo canti, ell canta; valencià jo cante, ell canta; balear i alguerès jo cant, ell canta, però, en canvi, jo perd, ell perd i jo sent, ell sent (no en valencià, que ha velaritzat la primera persona: jo perc, ell perd i jo senc, ell sent).

9. El nord-occidental coneix també altres procediments per a defugir la coincidència formal, com els que trobem en el mode subjuntiu, en què la - a final indica primera persona mentre que la tercera es resol per altres vies: que jo canta enfront de que ell canto, que ell cante o que ell canti; que jo cantessa davant de que ell cantés.

Caplletra 61 (Tardor, 2016), pp. 165-209 
cap a $e$ de la vocal àtona final de la terminació -AT (Rasico I982: 95, n. 276; Wheeler 2007 [1993b]: I08). ${ }^{10}$

Aquesta suposició s'enfronta, però, a algunes incerteses. En primer lloc, podem plantejar-nos si tenim la seguretat que totes les consonants finals provoquessin el tancament de la -A àtona precedent. I, en cas afirmatiu, podríem demanar-nos si el tancament es produiria en el mateix període per a totes les consonants. És ben clar que hi va haver un procés de tancament de -As en -es que va afectar els plurals dels elements nominals (ROSAS > roses, BONAS > bones) i les formes verbals de segona persona (CANTABAS > cantaves, BATTAS > bates). També és clara la mutació de -ANT en -en per la qual van passar les formes verbals de sisena persona (CANTANT > canten), tot i que no sabem si tots dos processos van operar alhora o van ser successius $i$, en aquest darrer cas, quin pes pot haver tingut el primer en el segon: sigui com sigui, les grafies del tipus -es s'escolen en els textos força abans que les grafies del tipus -en (Rasico 1982: 93). ${ }^{11}$

D'altra banda, sembla menys general el procés de tancament cap a [e] de la A posttònica interior en les persones quarta i cinquena de les formes verbals. Cantàvem (< CANTABAMUS) i cantàveu (< CANTABatis) es pronuncien cantàv $[\varepsilon] m$ i cantàv $[\varepsilon] u$ (o cantà $[\varepsilon] m$ i cantà $[\varepsilon] u$, o cantà $[j \varepsilon] m$ i cantà $[j \varepsilon] u$ ) a l'àrea central del nord-occidental (Creus 2002: 52-59), ${ }^{12}$ en la mateixa zona en què la -A final àtona s'articula $[\varepsilon]$ (i,

IO. Wheeler (2007 [1993b]: I08) defensa l'origen fonètic de la duplicitat catalana de resultats de la terminació llatina -AT: «En la majoria dels dialectes catalans els canvis (2c) i (2d) es produïren en l'ordre donat, amb el resultat que els morfs llatins -AM i -AT es confonen en /a/. Un tret característic del nord-occidental, amb conseqüències morfològiques molt importants, és que el canvi $(2 \mathrm{~d})$ s'operà abans del canvi (2c), de manera que -AT va donar/-e/, mentre que -AM va donar/-a/». Tanmateix, en un treball anterior, Wheeler (1984: 4I3-4I4) es decantava per la possibilitat d'un origen analògic de la terminació - e («Aquesta /-e/ en la za persona del singular pot ser heretada del català primitiu, però creem més probable un origen analògic»), tot i que hi arribava per una via diferent de la que proposem nosaltres en el present article: «El punt de partida seria la /-e/ de la 3 a persona del singular del subjuntiu. Les forces influenciadores serien la sincrètica "subjuntiu = indicatiu" del paradigma originari, i el model tendint a distingir la za de la ia persona mitjançant la /e/ eixida del plural en -en o de la za persona del singular en -es. O, posant-ho a l'inrevés, una /-a/ no encaixava gaire bé en un present, en un indicatiu, en una za persona, sobretot després de la substitució de -am, -au per -em, -eu en l'indicatiu de la Conjugació I». Wheeler (2007 [1993b]: I08, n. 6), però, se’n desdiu explícitament: «Un canvi analògic, afectant, entre altres formes, la forma base (tercera persona del present d'indicatiu) del paradigma de la classe flexional estable (conjugació I) és ben improbable del punt de vista de la Morfologia Natural. Ara interpretem aquesta característica del dialecte nord-occidental com a resultat d'un ordre distint dels processos històrics».

II. Els primers exemples que reporta aquest autor són Cabanes (854), en el primer cas, i frangien (I043-III7), en l'altre.

I2. «a partir de les nostres dades no hem pogut constatar un fenomen que hem trobat exposat en algun dels treballs esmentats i que consisteix a estendre la conversió de /a/ en [e] en posició de síl.laba travada. D’aquesta regla en sorgeixen formes com cantàv [e] $m$ o cantàv [e] u que nosaltres — conscients, però, de la restricció geogràfica de les nostres dades — sempre hem constatat com a formes amb [E]» (Creus 2002: 59). 
crucialment, es realitzen cantàv[a]m, cantàv[a]u en una localitat com Arbeca (les Garrigues), que no ha arribat a l'articulació $[\varepsilon]$ de /a/ en posició àtona final). Pel que fa a la realització actual a la zona en què va gestar-se el català occidental naixent, aquesta vocal àtona s'ha velaritzat i labialitzat. Cantàv[o]m i cantàv[o] $u$, qualificades sovint de formes pallareses, es recullen encara avui, especialment en pobles petits i en parlants grans, per tot el Pirineu de parla occidental, inclòs l'Alt Urgell i Andorra (Massanell 2OII, 20I2). Aquesta labialització i velarització de la vocal àtona s'explica per assimilació, provocada pel contacte amb les bilabials $[\beta]$ i $[\mathrm{m}]$ i amb la labiovelar $[\mathrm{w}]$ (Veny I998: 99), i tant es podria haver acomplert a partir d'una realització prèvia [e] com [a].

Fora de la morfologia verbal i dels plurals, els casos en què es pot adduir el tancament en [e] de A posttònica són escassos, tot i que no rars (Badia i Margarit I981: \$62; Moll I99I: 87). ${ }^{13} \mathrm{~A}$ vegades, costa de definir-se sobre si tenen una naturalesa purament fonètica o bé si responen a la generalització de terminacions més abundants. Així, a rave (< RAPHĂNU), orgue (< ORGĂNU) i orfe (< ORPHĂNU), s'hi pot veure simplement el tancament de A per la posició posttònica, o bé es pot pensar en la pressió analògica exercida per les paraules que acabaven en $-e(n)$ a partir d'altres terminacions (home < HŎMĬNE, verge < VĬRGĬNE, marge < MARGĬNE, ase < ASĬNU, cove < CŎPHĬNU, jove < IŬVĔNE, etc.), les quals tenien $e$ com a resultat regular de Ǐ o Ě i podien atreure el grup menys nombrós procedent de -ĂNU, més quan una - $e$ final encaixa millor en un masculí que no pas una $-a$.

Aquestes reflexions tenen com a objectiu posar de manifest que, més enllà dels processos de tancament -AS > -es i -ANT > -en, generals i ben establerts (Rasico I982: 87-96), podem plantejar-nos un dubte raonable sobre la naturalesa purament fonètica de la transformació en [e] de la A posttònica llatina en altres contextos, i en particular en la terminació -AT de tercera persona.

\subsection{LA FORÇA DELS PARADIGMES}

Atès que la hipòtesi de l'origen fonètic de la - e final de tercera persona, tot i que no és descartable, planteja algunes incerteses, es pot assajar de buscar un altre detonant per a l'aparició de formes del tipus cante, cantave o cantarie. Com mostra la taula 4,

13. A banda dels tres que recollim en aquest paràgraf, se solen esmentar cànem (< CANNĂBE) i ànec (< ANĂTE), aquest darrer amb canvi evident de terminació, potser influït per mots com mànec (< MANǐCU), amb - e obtinguda regularment a partir de la İ breu llatina. I s'hi podrien afegir estómac (< STOMăcHU) i pèlag (< PELĂGU), si obviem la forma que ha sentenciat la normativa i ens fixem en grafies medievals com estomech o pelech (DCVB, s.v.).

Caplletra 61 (Tardor, 2016), pp. 165-209 
les terminacions verbals àtones dels paradigmes catalans més antics contenien només dues possibles vocals: la $a$ i la $e$. La $a$ ocorria habitualment a la primera persona i a la tercera, mentre que la $e$ es trobava a la segona i a la sisena. ${ }^{14}$ Es pot pensar, doncs, en una expansió d'aquesta $e$ cap a la tercera persona, pel fet que comportava diversos avantatges, com exposarem a partir del cas de l'imperfet d'indicatiu, que pensem que és el temps on es va iniciar el canvi.

En primer lloc, i més important, la innovació trencava el sincretisme entre la primera persona i la tercera (jo cantava, ell cantave). Aquest canvi es veia afavorit pel principi de transparència, ja que s'assolia que cada forma desenvolupés una única funció: primera persona de l'imperfet d'indicatiu, en el cas de cantava, i tercera persona de l'imperfet d'indicatiu, en el de cantave. Secundàriament, també es pot considerar que es guanyava en uniformitat, atès que dels dos al.lomorfs d'imperfet d'indicatiu existents, va i ve, s'expandia l'ús de ve (cantaves, cantave, cantaven), que passava a ser l'al.lomorf majoritari, i es restringia l'ús de $v a$, que quedava identificat amb la primera persona (cantava). A més, el canvi anava en la línia del principi d'iconicitat estructural, que afavoreix els paradigmes en què les formes gramaticals més marcades morfosintàcticament són també les més marcades formalment: la primera persona, més marcada que la tercera, era la que es quedava amb el segment restringit $v a$, mentre que la tercera persona, menys marcada, adoptava el segment genèric ve i passava a distingir-se de la sisena persona (o tercera del plural) simplement per l'absència o la presència de la marca $-n$. En tot cas, el canvi suposava una ascensió en l'escala o jerarquia d'iconicitat, perquè partint d'un estadi de manca d'iconicitat (jo cantava / ell cantava: la categoria marcada funcionalment, la primera persona, té la mateixa forma que la no marcada, la tercera persona) s'elevava a un estadi de mínima iconicitat (jo cantava / ell cantave: la categoria marcada funcionalment té una forma diferent de la categoria no marcada). ${ }^{15}$

I4. No ens pronunciem sobre si les persones quarta i cinquena contenien $a$ o $e$, o si hi alternaven totes dues (com en els dialectes actuals). En realitat, no és rellevant per a la nostra argumentació, atès que la quarta i la cinquena persones formen una unitat amb característiques pròpies en molts temps verbals, amb diferències accentuals i desinencials, com mostra el present d'indicatiu (canto, cantes, canta, cantem, canteu, canten) i el present de subjuntiu (canti, cantis, canti, cantem, canteu, cantin). També s'esdevenia en llatí, amb un abast encara més ampli, que afectava, per exemple, l'imperfet d'indicatiu (CANTÁBAM, CANTÁBAS, CANTÁBAT, CANTABÁMUS, CANTABÁTIS, CANTÁBANT), i que començava pel fet mateix que les marques de les persones I, 2, 3 i 6 eren asil-làbiques $(-\mathrm{M},-\mathrm{S},-\mathrm{T},-\mathrm{NT})$ mentre que les marques de les persones 4 i 5 eren sil-làbiques (-MUS, - TIS). I5. Els altres dos graus de la jerarquia, els extrems, són: en el nivell més baix, la contraiconicitat (la categoria marcada funcionalment té una forma més reduïda que la no marcada) i, en el nivell més alt, la màxima iconicitat (la categoria marcada funcionalment s'obté afegint una marca formal a la no marcada). Un exemple clar de contraiconicitat es trobava en la relació entre la primera persona i la tercera del present d'indicatiu de la 
Aquests avantatges que hem exposat per a l'imperfet d'indicatiu són traslladables exactament a un temps menys emprat com és el condicional $i$, de fet, pensem que el sorgiment de les formes amb - e devia iniciar-se efectivament en el primer i expandir-se posteriorment cap al segon. Suggerim aquest ordre en la generació (ell cantave) i en l'expansió (ell cantave $\rightarrow$ ell cantarie) de les formes de tercera persona amb -e pel fet lògic que les transformacions solen generar-se en els temps més emprats, de la mateixa manera que acostumen a iniciar-se en les conjugacions amb més abundor de verbs i més productives.

A diferència dels temps que hem esmentat fins ara, en el cas del present d'indicatiu dels verbs de la primera conjugació, en què no hi havia sincretisme entre la primera persona i la tercera (jo cant, ell canta), la mutació cap a cante pot semblar injustificada. ${ }^{16} \mathrm{Si}$ ampliem la visió al conjunt del sistema verbal, però, es fa evident que una forma de tercera persona del present d'indicatiu del tipus cante encaixa millor que una del tipus canta quan ja s'ha associat la - $e$ final a tercera persona en altres temps verbals com l'imperfet d'indicatiu i el condicional (ell cantave, ell cantarie $\rightarrow$ ell cante). La penetració del canvi en el present d'indicatiu dels verbs de la primera conjugació obeeix, per tant, al principi de congruència del sistema, pel qual es veuen afavorits els paradigmes que s'organitzen de manera uniforme i sistemàtica d'acord amb els paràmetres morfològics de la varietat lingüística: en aquest cas, s'harmonitza la representació de la tercera persona, que s'associa a la marca - e a través de diversos paradigmes del sistema. A més, també se'n veu beneficiada la uniformitat intraparadigmàtica del present d'indicatiu, atès que la mutació cap a - $e$ a la tercera persona suposa la uniformització amb un únic al-lomorf, $e$, de totes les formes del paradigma que tenien vocal àtona: $[$ cant $]$, cantes, canta, $[$ cantam $],[$ cantau $]$, canten $\rightarrow[$ cant $]$, cantes, cante, [cantam], [cantau], canten. Malgrat l'absència de sincretisme, doncs, la mutació

primera conjugació, tant abans com després del canvi: jo cant, ell canta; jo cant, ell cante. La màxima iconicitat es podria considerar que s'havia assolit en la relació entre ell cantave i ells cantaven, en què la tercera persona del plural, més marcada funcionalment que la tercera persona del singular, s'obtenia afegint la marca $-n$ a aquesta. I6. I fins es podria percebre com a desavantatjosa en els casos en què la primera persona del present d'indicatiu rebia una vocal de suport per raons sil-làbiques, atès que llavors el canvi generava sincretisme: jo sembre / ell sembra $\rightarrow$ jo sembre / ell sembre, i més quan aquesta vocal de suport es va acabar morfologitzant i expandint a totes les primeres persones dels verbs de la primera conjugació. Val la pena d'apuntar que el canvi de la terminació de tercera persona cap a - e en nord-occidental tindrà repercussions importants en l'evolució posterior de la primera persona del present d'indicatiu: aquesta s'ha mantingut com a -e (jo cante) en els dialectes en què la tercera persona roman com a $-a$, mentre que es va mudar en $-o$ (nord-occidental i central) o en $-i$ (septentrional) en els dialectes en què hi havia sincretisme entre la primera i la tercera persones (jo cante / ell cante, amb [e]; jo cante, ell canta, amb [ə]) (Pérez Saldanya I998: I27-I46). La diferència entre el nord-occidental i el valencià en la terminació de tercera persona, doncs, acabarà provocant també la diferència de terminació entre aquests dos dialectes a la primera persona.

Caplletra 61 (Tardor, 2016), pp. 165-209 
al present d'indicatiu és previsible que seguís, sense gaire distància, la mutació en el condicional i en el focus originari, l'imperfet d'indicatiu.

No hem esmentat encara el present de subjuntiu de les conjugacions no primeres. També en aquest cas hi havia sincretisme (que jo bata, que ell bata) i la mutació cap a la $-e$ de la tercera persona afavoria la transparència del paradigma. Tanmateix, els modes marcats - i el subjuntiu ho és - admeten el sincretisme amb més facilitat que els altres: «el sincretisme d'una categoria resulta més acceptable en contextos on aquesta categoria s'associa amb una altra de marcada» (Pérez Saldanya 1998: 156). Així doncs, la coincidència formal entre la primera persona i la tercera és més admissible en el mode subjuntiu que no pas en el mode indicatiu, raó per la qual suposem que la mutació havia d'arribar-hi tardanament, un cop consolidat el canvi en els temps d'indicatiu. Segons això, l'ordre que suggerim en aquest cas ubica el present de subjuntiu a la cua de les transformacions, com queda reflectit a la taula 5:

Taula 5. Esquema de l'expansió de la terminació - $e$ de tercera persona des de l'imperfet d'indicatiu al condicional, al present d'indicatiu de la primera conjugació i, finalment, al present de subjuntiu dels verbs de les conjugacions no primeres

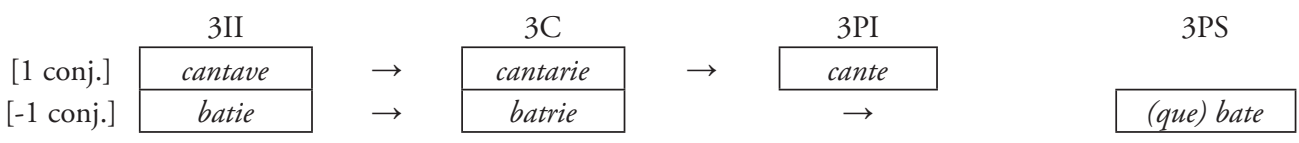

\section{ELS TESTIMONIS ESCRITS}

S'han formulat, doncs, dues hipòtesis per a explicar l'origen de les formes verbals de tercera persona acabades en -e. D'una banda, la hipòtesi de l'origen fonètic, que suposa que en el català occidental naixent la pèrdua de la -T final llatina es va produir més tardanament que en el català oriental $\mathrm{i}$, en concret, amb posterioritat al tancament de A final en síl.laba travada: per tant, la vocal de la terminació -AT se’n va veure afectada (CANTAT $>$ cantet $>$ cante). De l'altra, la hipòtesi de l'origen morfològic, que parteix de formes de tercera persona en $-a$, la transformació de les quals es veuria impulsada pel rebuig al sincretisme amb la primera persona, rebuig que és constatable actualment en el català nord-occidental i en els processos de canvi que afecten aquest dialecte.

Per a mirar d'escatir quina de les dues hipòtesis s'ajusta més a la realitat dels fets, cal recórrer als textos més remots que es conserven escrits parcialment o totalment en català, bo i sent conscients, però, que l'escassesa de testimonis i la seva fragmentarietat pot fer que projectin sobre aquest problema només una llum tènue. 


\section{I. DELIMITACIÓ DEL CORPUS}

Els textos amb què treballem els hem obtingut del Corpus Informatitzat del Català Antic (CICA) (<www.cica.cat>), dirigit per Joan Torruella (UAB-ICREA), Manuel Pérez Saldanya (UV-IEC) i Josep Martines (UA-IEC). Com que és un corpus nolematitzat, n'hem extret les versions completes dels documents i n'hem fet el buidatge manual. Hem seleccionat els textos de l'època arcaica de l'idioma, dels segles XI i XII, i hi hem inclòs tot el XIII, tot i que a la segona meitat de segle se sol considerar superat aquest període. ${ }^{17}$ Hem fet la cerca dels documents marcats com a nord-occidentals, ${ }^{18}$ perquè les dades que necessitem hem de trobar-les en els primers textos de la llengua catalana i concretament en els que procedeixen dels comtats d'Urgell i de Pallars i del bisbat d'Urgell. Tot i que els testimonis escrits de l'etapa arcaica de la llengua són escassos, n'hi ha un nombre significatiu que prové justament d'aquesta àrea: «les terres de l'antic comtat d'Urgell presenten avui dia el major repertori de documents en català arcaic» (Moran \& Rabella 200I: 32).

Aquests documents aplegats en el CICA que constitueixen el nostre corpus d'estudi provenen de quatre fonts: Russell-Gebbett 1965 (referència de font: MCLT); Moran \& Rabella 200I (referència: PTLC); Soberanas, Rossinyol \& Puig 200I (referència: $H O$ ); Rasico 2006 (referència: $E C A$ ). Un cop seleccionats els textos que aporten dades rellevants, ${ }^{19}$ el corpus ha quedat constituït per una trentena de documents, que són els que recollim a la taula $6:^{20}$

17. Més endavant, la presència de la - e de tercera persona en textos nord-occidentals haurà assolit un grau de consolidació tal que ja no ens pot informar sobre el procés pel qual s'hi ha arribat. Així, Veny (I993: I2I-203), en l'estudi del Regiment de preservació de pestilència de Jacme d'Agramont, del segle XIV (redactat el I348 i que ens ha pervingut en un manuscrit de 1387), conclou: «L'ús sistemàtic de la -e com a marca de tercera persona és evident. A la taula verbal s'hi registren gairebé 250 formes amb -e (exactament: 247). En canvi, el nombre de variants amb - $a$ és insignificant; només en trobem 4 (escalfa i se pega, al Present d'Indicatiu, i corrompa i tolga, al de Subjuntiu) que constitueixen el migrat tribut al sistema fonètico-morfològic de la que anomenaríem llengua general» (p. 150).

I8. A vegades la marca era simplement «occidental».

19. N'han quedat al marge, perquè no contenen cap de les formes verbals que analitzem en aquest article: Jurament feudal I (I028-I047, PTLC, p. 46), Acords feudals 2-4 (I055-I098, MCLT, p. 68), Jurament de pau i treva del comte Pere Ramon del Pallars Jussà al bisbe d'Urgell (I098-III2, PTLC, pp. 64-65), Inventari 2 (I239, MCLT, p. 96), Lletres en català als bisbes d'Urgell 2-II/III (I230-I255, ECA, pp. 399-402) i Lletres en català als bisbes d'Urgell 3-IX/XI/XIVIXV/XVI/XVIII (I257-I269, ECA, pp. 403-407).

20. Les cerques en el $C I C A$ han proporcionat dos textos repetits, introduïts des de dues fonts diferents: Cartes al bisbe d'Urgell-I (MCLT, 1259, pp. I08-109) coincideix amb Lletres en català als bisbes d'Urgell 3-X (ECA, I257-I269, pp. 403-407) i Cartes al bisbe d'Urgell-2 (MCLT, I257-I269, pp. I08-I09) coincideix amb Lletres en català als bisbes d'Urgell 3-XVII (ECA, I257-I269, pp. 403-407). Hem considerat només la versió de MCLT, que contenia una datació més precisa en el primer cas.

Caplletra 61 (Tardor, 2016), pp. 165-209 
Mar Massanell i Messalles

Sincretisme i canvi morfològic: evolució de la terminació verbal en -AT en català

Taula 6. Textos que integren el corpus d'estudi, extrets del CICA. Corresponen als documents dels segles XI, XII i XIII que són de procedència nord-occidental (dels antics comtats d'Urgell i de Pallars) i que contenen formes rellevants per al nostre estudi (3PI [I conj.], ${ }_{3} \mathrm{II},{ }_{3} \mathrm{C},{ }_{3} \mathrm{PS}$ [-I conj.])

\begin{tabular}{|c|c|c|c|}
\hline Núm. & Document & Datació & Font \\
\hline 1 & Disputació referent als limits entre Guissona $i$ Ribelles & $1036-1079$ & MCLT, p. 65 \\
\hline 2 & Jurament feudal 2 & $1043-1098$ & MCLT, p. 66 \\
\hline 3 & Acords feudals 1-1 & $1043-1098$ & $M C L T$, p. 67 \\
\hline 4 & Acords feudals 1-2 & $1043-1098$ & MCLT, p. 67 \\
\hline 5 & Acords feudals 2-3 & mitjan XI & MCLT, p. 68 \\
\hline 6 & Jurament feudal de fidelitat & $1047-1098$ & PTLC, p. 54 \\
\hline 7 & Greuges de Guitard Isarn, senyor de Caboet & $1080-1095$ & PTLC, pp. 58-60 \\
\hline 8 & Acords feudals 3-5 & $1094-1110$ & $M C L T$, pp. 68-69 \\
\hline 9 & Acords feudals 3-6 & 1117 & MCLT, pp. 68-69 \\
\hline 10 & Llibre dels judicis 1 & 1a meitat XII & PTLC, pp. 77-78 \\
\hline 11 & Greuges dels homes de Sant Pere de Graudescales & XII & PTLC, pp. $68-70$ \\
\hline 12 & Greuges dels homes d'Hostafrancs & $\mathrm{XII}^{21}$ & $E C A$, pp. $278-279$ \\
\hline 13 & Homilies d'Organyà & 1204 & $H O$, pp. $117-125$ \\
\hline 14 & Rendició del castell de Llorenç & 1211 & PTLC, p. 98 \\
\hline 15 & Donació d'oliverars per part de Ramona de Solans i altres & 1241 & MCLT, p. 97 \\
\hline 16 & Queixes de l'església de Puigfalconer & 1242 & MCLT, pp. 98-99 \\
\hline 17 & Controvèrsies a l'entorn de l'església d'Organyà-1 & 1243 & MCLT, pp. 100-101 \\
\hline 18 & Controvèrsies a l'entorn de l'església d'Organyà-2 & $1243-1250$ & MCLT, pp. 100-101 \\
\hline 19 & Lletres en català als bisbes d'Urgell 1 & 1244 & ECA, pp. 398-399 \\
\hline 20 & Donació de terres al Pallars per part de A. Assalid & 1248 & MCLT, p. 104 \\
\hline 21 & Disputació entre R. Maasen i Ferrer d'Escales & $1250-1255$ & MCLT, p. 105 \\
\hline 22 & Lletres en català als bisbes d'Urgell 2-IV & $1230-1255$ & $E C A$, pp. 399-402 \\
\hline 23 & Lletres en català als bisbes d'Urgell 2-VI & c. 1251 & $E C A$, pp. 399-402 \\
\hline 24 & Lletres en català als bisbes d'Urgell 3-VII & $1257-1269$ & $E C A$, pp. $403-407$ \\
\hline 25 & Lletres en català als bisbes d'Urgell 3-VIII & $1257-1269$ & $E C A$, pp. $403-407$ \\
\hline 26 & Lletres en català als bisbes d'Urgell 3-XII & $1257-1269$ & $E C A$, pp. $403-407$ \\
\hline 27 & Lletres en català als bisbes d'Urgell 3-XIII & $1257-1269$ & $E C A$, pp. $403-407$ \\
\hline 28 & Cartes al bisbe d'Urgell-1 & 1259 & MCLT, pp. 108-109 \\
\hline 29 & Cartes al bisbe d'Urgell-2 & $1257-1269$ & MCLT, pp. 108-109 \\
\hline 30 & La venda del castell d'Altés & 1288 & $E C A$, pp. 339-343 \\
\hline
\end{tabular}

2I. Malgrat que en el CICA aquest document està introduït en el subcorpus de la segona meitat del segle XIII, en l'obra de Rasico hi apareix amb la referència «Segarra, segle XII». Ens hem ajustat, doncs, a aquesta datació. 


\section{I.I. Tipologia de textos i característiques}

El corpus objecte d'estudi aplega fonamentalment textos vinculats a la societat feudal. Així, s'hi troben juraments de fidelitat (documents 2 i 6), acords feudals (doc. 3, 4, 5, 8 i 9), donacions de terres (doc. I5 i 20), una rendició d'un castell (doc. I4) i la venda d'un altre (doc. 30), i força textos relacionats amb la denúncia de conflictes, tan freqüents en la societat feudal, violenta i inestable: disputacions (doc. I i 2I), greuges (doc. 7, II i I2), queixes (doc. I6) i controvèrsies (doc. I7 i I8). També hi ha materials epistolars: cartes als bisbes d'Urgell, totes del segle XIII (doc. I9 i del 22 al 29). Uns i altres són textos breus - molt breus, a vegades. A banda d'aquests documents, que constitueixen el gruix del corpus, n'hi ha dos de singulars: el Llibre dels judicis I i les Homilies d'Organyà.

El Liber iudiciorum és una compilació de lleis que es va aplegar al segle vir per a unificar la legislació de gots i hispans, i que posteriorment va ser respectada pels francs. Durant el segle XII se'n va fer la traducció al català — la primera a una llengua romànica, sembla_- de la qual avui només se'n conserven dos fulls, que havien estat emprats com a guardes de llibres. El primer fragment, que va donar a conèixer Anscari M. Mundó el I960, és el més tardà (II80-II90) i sembla que prové del bisbat de Girona. El segon, conservat a l'Arxiu de la Catedral d'Urgell, que va ser descobert per Cebrià Baraut, és més antic (de la primera meitat del segle XII) i presenta un estadi de llengua «més arcaic i de caràcter pirinenc» (Moran \& Rabella 200I: 75-82).

Aquest fragment més antic i de procedència urgellesa del Llibre dels judicis és el que forma part del corpus d'aquest article, tot i que és evident que es tracta d'un tipus de text de característiques molt diferents dels documents feudals que l'acompanyen. No podem oblidar que és un fragment de la traducció d'una obra llatina formal i culta. Respon, doncs, a un registre lingüístic molt més elaborat que el que es troba en els juraments de fidelitat, en els acords feudals o en els reculls de greuges.

L'altre document singular són les Homilies d'Organyà. Des que el 8iz el concili de Tours ordenés de traduir les homilies llatines in rusticam Romanam linguam, en la predicació s'usava la llengua del poble. La reforma gregoriana de l'Església, iniciada la segona meitat del segle XI, va impulsar, entre altres actuacions, els aplecs d'homilies escrites en vulgar, que seguien la tradició dels homiliaris llatins i tenien l'objectiu de millorar la predicació. La canònica de Sant Ruf d'Avinyó va elaborar reculls d'homilies en llengua occitana, els quals van ser distribuïts per les canòniques catalanes en el tombant del segle XII al XIII, com testimonien les Homilies de Tortosa, escrites en occità, per bé que amb fragments catalanitzats (Moran I990). En aquest context, les Homilies d'Organyà, que estan escrites en llengua catalana, s'han considerat tradicionalment 
una traducció de l'occità al català — de Griera (1917) a Moran (1997)—, traducció que seria la primera coneguda entre llengües romàniques i que implicaria l'existència, ja en aquest període, d'una consciència de diferenciació lingüística entre ambdues llengües. Més recentment, però, Puig (200I: 206) ha aportat arguments a favor de l'origen directament català del text de les Homilies d'Organyà, amb l'excepció de l'homilia IV, que sí que seria una adaptació — més que no pas una simple traducció- d'una homilia en occità: "les Homilies d'Organyà, llevat de la quarta, són obra original d'un autor-redactor autòcton que ha produït directament un text català a partir de fonts llatines. I, si bé aquest text integra un cert nombre d'occitanismes, no és traducció de cap original occità». ${ }^{22}$ Com a exemple, a partir de l'homilia I, Puig (200I: 207) mostra com «l'autor s'expressa de manera genuïna i quasi personal, amb fluïdesa i encert. És una homilia probablement "pensada" en català, almenys en la primera part, amb jocs de paraules ("caritad"- "car", IVI9-2I), ús de significacions dobles (caritat com a amor i caritat com a almoina) i frases amb ritme intern (2rio: "cel qi dóna almosna, a sson proxme fa bé e a Déu plader")».

Les Homilies d'Organyà van ser descobertes per Joaquim Miret i Sans, que el $1904^{23}$ les va donar a conèixer com "el més antig text literari escrit en català», qualificació que ha perdurat en el temps. Possiblement la consideració de literari és deguda més al contrast amb els textos precedents i coetanis — breus, simples, utilitaris— que a les característiques mateixes del document: un recull de sermons per a facilitar l'activitat oratòria dels clergues, que mostra una llengua popular, si bé de construcció més complexa, això sí, que la dels documents feudals (Moran \& Rabella 200I: 13-34). Una altra diferència amb la resta de textos del corpus és l'extensió: les Homilies d'Organyà, de les quals ens han pervingut vuit folis, és el document més extens amb diferència i el que aportarà un nombre més elevat de formes rellevants.

Un tret fonamental dels textos que integren aquest corpus, especialment dels més antics, és la barreja de fragments llatins —escrits en un llatí macarrònic_- i

22. Segons Puig (200I: 198), la presència d'occitanismes — com també de fragments llatins_ és justificable sense recórrer a la idea de la traducció: «Pel que fa als pocs occitanismes de les Homilies, cal dir que se situen majoritàriament en l'àmbit del llenguatge jurídic arrelat en el feudalisme; és a dir, es tracta de mots manllevats a l'occità però que poden haver estat plenament integrats en la llengua catalana i que poden funcionar com a vocabulari propi i no forà. En canvi, la presència del llatí denota el respecte per la llengua sacra i culta, la llengua en què se celebra la litúrgia i en què es transmet la cultura. L'ús del llatí en l'homiliari d'Organyà demostra que els nostres sermons no són traduccions d'aquesta llengua. Si ho fossin, no inclourien cap frase llatina, ja que tot hauria estat traduït».

23. De fet, van publicar-se al número 7 de la Revista de Bibliografia Catalana, el qual, malgrat que porta data de 1904, va aparèixer el 1907, com acredita el peu d'impremta (Rossinyol \& Soberanas 2004: 8). 
catalans. Aquesta circumstància provoca, per a la tercera persona, la convivència de formes verbals llatines amb la terminació - at (en una ocasió grafiada - ad) ${ }^{24}$ i de formes verbals catalanes, que són les que hem extret en el buidatge, acabades en $-a$ o en $-e$. En donem una petita mostra, corresponent al document I (Disputació referent als limits entre Guissona i Ribelles, I036-I079):

[...] et monstre Remon ipso termine ke proclame per Ribeles, que est de Cion ad enlà, che ag tan ample lo monstre de là kom lo té de [za] ad riba de Scio. Et si $\cdot n$ fan batalla et suo omine de Remon Gonball y venz, ut predicto episcopo feneschat ad jam dicto Remon Gonball ipso termine, et emendet ipso malo quod ibi apreenderit ipso kavallario de Reimundo sic quomodo fuerit judicatum per directum. Et si ipso suo omine de domno epíscopo y venz, similiter fenescat Remon G. ipso termine [...] et si í venz ipso suo omine de domno episcopo, quod Remon Gonball li •ó jakescha e li ó defenescha per escrito; et si ipso suo omine í venz de Remon Gonball, similiter fenescat et jakescat ipso epíscopo per escrito. E ke sia en so assemblament de ipso epíscopo si -ó farà el primerr [...] aut ó rechulirà de Remon Gonball; et en quale que remanserit [...] ipsa batalla, similiter jakescat et feneschat per exvacuatio scripture. Et ipso die que metrant illorum cavalers in potestate de ipsos omines quin faciant ipsa batalla, dicat ipso epíscopo si pharà $\cdot n$ el primers ipso fromiment $[\ldots] \mathrm{o} \cdot 1$ rechulirà de Remon Gonball.

\section{I.2. Origen dialectal dels textos}

Adscriure un document antic a un determinat dialecte no resulta obvi. D'una banda, les fronteres dialectals actuals, en les quals es basa la divisió dialectal que tenim en ment, no han de coincidir necessàriament amb les fronteres dialectals dels segles anteriors. D'una altra, els textos escrits quasi mai no permeten d'elaborar una fitxa sobre «l'informant» amb el control de tots els aspectes que el mètode geolingüístic ha fet evident que cal tenir en compte per a garantir la validesa dialectal de les dades recollides. De fet, en molts textos, especialment en els més reculats, ni tan sols se sap qui n'és l'autor; en d'altres, hi figura qui l'ha fet escriure - la correspondència podia ser dictada pel remitent - i només en alguns consta l'autor material del text - per exemple, un notari. Així doncs, sovint basem l'assignació dels documents a un dialecte determinat en funció dels topònims que s'hi esmenten, dels personatges que hi surten citats o de l'arxiu on es conserven. No ha estat diferent en el cas dels textos que analitzem.

24. "Comandad Raimundus comes ad Bonfilg illum castellum de Alta Riba» [doc. 4, Acords feudals I-2, I043-I098]. En el mateix text, però: «Et si de Raimundo comite minus venit, que así ó atendat Bonfilg ad ipso suo filio de Raimundo comite». I, encara, una forma que ja podem considerar catalana: "per illas oras que Raimundus comes demanda potestatem». 
Al document I s'hi esmenta Guissona (la Segarra) i Ribelles, avui al municipi de Vilanova de l'Aguda (la Noguera); al 3, Mont-ros, avui al municipi de la Torre de Cabdella (el Pallars Jussà); al 7, Caboet —avui Cabó- i Ares, topònims de la vall de Cabó (l'Alt Urgell), i Rialb, una altra vall als límits entre el Pallars Jussà, la Noguera i l'Alt Urgell; al 8, Salàs (el Pallars Jussà); al 9, Galliner, avui al municipi d'Orcau (el Pallars Jussà); al ı2, Hostafrancs de Sió, avui al municipi dels Plans de Sió (la Segarra); al I5, Solans, avui al municipi de Guils del Cantó, i Ares, avui al municipi de Cabó, ambdós a l'Alt Urgell; al ı6, Tremp (el Pallars Jussà); al I7 i al I8, Organyà (l'Alt Urgell); al 20, Bernui, avui al municipi d'Altron (Pallars Sobirà); al 2I, Fígols i Organyà, ambdós a l'Alt Urgell; al 30, el castell d'Altés, avui al municipi de Bassella (l'Alt Urgell).

Els documents 2 i 6 són juraments feudals de fidelitat fets a Ramon V, comte de Pallars Jussà entre I047 i rog8. També s'esmenta aquest comte en els documents 4 i 5 , que són acords feudals. El document to és el fragment del Llibre dels judicis que va ser localitzat a l'Arxiu de la Catedral d'Urgell. El I3 correspon a les Homilies d'Organyà, procedents del priorat d'Organyà (l'Alt Urgell). El document I4 és la rendició de Guerau de Cabrera davant del rei Pere el Catòlic, que l'havia assetjat al castell de Llorenç (avui al municipi de Sant Llorenç de Montgai, la Noguera), en el marc de la disputa nobiliària per la successió del comtat d'Urgell després de la mort d'Ermengol VII sense descendència masculina.

El document 19, malgrat el títol (Lletres en català als bisbes d'Urgell I), no té una estructura epistolar, sinó que és un acord entre Ponç, bisbe d'Urgell, i Roger, comte de Foix, la veu dels quals es va alternant al llarg del text, que consta per qui va ser escrit: «B[er]nardus Veciad not[arius] public[us] Sedis Urgell[e]n[sis] h[oc] sc[ri]psit et sup[er]sc[ri]psit i[n] .III. lin[e]a p[er] la gràcia d[e] Déu». Els documents 22 a 29 sí que són cartes adreçades al bisbe d'Urgell i totes duen la indicació del remitent: «d[e] mi frare B. d[e] Lirii comanador d[e] Vilam[ur]» (doc. 22 i 23), «d[e] mi G. d[e] Vilam[ur] peralad d[e] la casa d[e] Rib[er]a e d[e] tot lo co[n]ve[n]t d[e] la casa» (doc. 25 i 27), que remeten totes quatre a la jurisdicció feudal de Vilamur, inclosa al comtat de Pallars; «d[e] mi en R. d'Orcad», variant arcaica d'Orcau (el Pallars Jussà) (doc. 24); «[de] [nós] [en] [A.] [Decano] [Monçon]» (doc. 26) —recordem que a Montsó, actualment vila aragonesa al límit amb la Llitera, i de parla castellana, s'hi parlava català en aquesta època i pertanyia al Principat de Catalunya, fins que el I305 Jaume II acordà l'establiment de la frontera catalanoaragonesa al curs d'aigua conegut com la clamor d'Almacelles; "del vostre humils capelà de Seró», poble avui del municipi de Tudela de Segre (la Noguera) (doc. 28), i «dels clerges e de tots los promes de Araós», poble avui inclòs al municipi d'Alins de Vallferrera (el Pallars Sobirà) (doc. 29). 
Hem exclòs del corpus tres documents, codificats com a nord-occidentals al CICA, perquè en trobem dubtosa l'adscripció a aquest dialecte. El primer, Queixes dels templers de Barberà (II90-I21O, MCLT, pp. 85-86), perquè se situa a la Conca de Barberà $\mathrm{i}$ aquesta comarca, tot i que limita amb el territori nord-occidental, està inscrita -almenys avui-en el català central. El segon, Abusos comesos a Lleida per Petrus de Lobeira (fi del xII, MCLT, pp. 90-9I), perquè és un text amb trets occitanitzants clars (rauberies, foron, malafaita, agron, etc.), malgrat els indrets que s'hi esmenten («Cosa sabida és que Petrus de Lobeira can enparà justícia de Lèrida se vanà t dis que aizò fazia per amor de Déu e per salvament de s'ànima e seria fidels a tot lo pobol de Lèrida t dominis»). El tercer, Lletres en català als bisbes d'Urgell 2-V (I230-I255, ECA, pp. 399-402), perquè sembla que el remitent de la carta és de la Cerdanya, concretament de Saga, avui municipi de Ger («d[e] mi A. d[e] Saga»), impressió que es veu reforçada per l'esment repetit de Puigcerdà. Val a dir que, abans de descartar-los definitivament, hem comprovat que no continguessin cap forma de $3 \mathrm{PI}, 3 \mathrm{II},{ }_{3} \mathrm{C}$ o $3 \mathrm{PS}$ acabada en $-e^{25}$

En canvi, hem incorporat al nostre corpus un document que en el CICA està codificat com a oriental — de manera lògica, atès els indrets que s'hi esmenten. Ens referim als Greuges dels homes de Sant Pere de Graudescales (s. XII), que hem numerat com a document II. Sant Pere de Graudescales, avui al municipi de Navès, queda a la part oriental de la comarca del Solsonès, que actualment està partida, des del punt de vista dialectal, entre el català nord-occidental i el català central, de la banda del qual cau la capital comarcal, Solsona, i també Navès (Veny \& Massanell 20I5: 133). Tanmateix, aquest document presenta formes de tercera persona amb - e final i, a més, sense alternança $a m b-a:{ }^{26}$ per raons lingüístiques, doncs, indubtablement l'hem d'adscriure al català nord-occidental. No insistim en el fet que les fronteres dialectals no són inamovibles al llarg dels segles, ni en la imprecisió que suposa classificar dialectalment els textos en funció dels topònims que contenen: són dificultats de caire metodològic de les quals és impossible de sostreure's.

Finalment, hem de justificar una darrera exclusió — tanmateix força òbvia—d'un dels documents que proporciona la consulta del CICA: hem prescindit dels Costums

25. A les Queixes dels templers de Barberà (II90-I2IO, MCLT, pp. 85-86), les formes que hi surten són: 3 PI demanda (3 ocurrències) i 3 PI geta. A Abusos comesos a Lleida per Petrus de Lobeira (fi del XII, MCLT, pp. 90-9I), s'hi poden llegir les formes de tercera persona d'imperfet d'indicatiu fazia, avia 4, trazia, era 2 i devia, i les de condicional seria, compraria, faria, daria, trairia i feria. A Lletres en català als bisbes d'Urgell 2-V(I230-I255, ECA, pp. 399-402), les formes que s'hi recullen són: 3 II valia, 3 II devia, ${ }_{3}$ PI garda i 3 PS faza.

26. Són aquestes: faie, solie, avie 3, ere, menave, volie 2 ; fóre, clamarie 2. 
Mar Massanell i Messalles

Sincretisme i canvi morfològic: evolució de la terminació verbal en -AT en català

de Tortosa (I272). D'una banda, provenen d'una àrea del nord-occidental, la tortosina, que queda fora de les terres on es va gestar el català occidental naixent -i que avui desconeix la tercera persona en - $e-i$, de l'altra, és una obra, de caràcter ciutadà $\mathrm{i}$ burgès, que ja no es pot considerar pertanyent al català arcaic del període feudal, sinó que correspon als inicis d'una nova etapa de desenvolupament ple de la prosa catalana.

\section{RECULL DE DADES I ANÀLISI}

Presentem l'anàlisi del corpus distribuït en tres seccions, marcades per la temporalitat i la naturalesa dels documents. En la primera, ens centrem en els textos dels segles XI i XII, inclòs el Llibre dels judicis I (documents I a I2). En la segona, abordem les Homilies d'Organyà (document 13), de 1204 , que mereix un tractament a part per la singularitat en el conjunt del corpus i per la riquesa de dades que l'extensió superior li permet d'aportar. Finalment, comentem la resta de textos del segle XIII (documents I4 a 30).

\section{I. ELS TEXTOS DELS SEGLES XI I XII}

Si en el català occidental naixent no hagués existit la terminació amb - a final a la tercera persona $\mathrm{i}$ les formes amb - $e$ fossin les més antigues $\mathrm{i}$ responguessin a un fet purament fonètic $(-\mathrm{AT}>-e t>-e)$, esperaríem que la documentació mostrés força regularitat en l'ús de la grafia $-e^{27} i$, sobretot, que no hi hagués diferències significatives en la representació amb - e de la vocal final de tercera persona entre els diversos temps verbals implicats, atès que res no justifica que l'evolució fonètica de la vocal posttònica es produeixi en moments diferents per a la forma de present d'indicatiu CANTAT o per a la forma de present de subjuntiu BATTAT, per a posar-ne un exemple. En canvi, no sembla que es compleixi ni una condició ni l'altra, segons es pot deduir del buidatge dels textos dels segles XI i XII, recollit a la taula 7 .

27. En les formes nominals de plural o en les verbals de segona persona en què havia operat el tancament de -AS en -es, la tradició gràfica llatina podia afavorir el manteniment de grafies amb $a$, malgrat que la pronúncia catalana ja fos estable com a [e]. En el cas de la tercera persona, la grafia llatina havia de tenir un pes inferior, atès que l'absència de la consonant final distanciava molt més la forma catalana amb - e de la llatina amb -AT. 
Taula 7. Buidatge de formes de tercera persona de l'imperfet d'indicatiu (3II), del condicional ( $\left.{ }_{3} \mathrm{C}\right)$, del present d'indicatiu (3 $3 \mathrm{PI})$ de la primera conjugació i del present de subjuntiu (3 $3 \mathrm{PS}$ ) de les conjugacions no primeres, corresponent als textos del corpus datats als segles XI i XII (documents I a I2)

\begin{tabular}{|c|c|c|c|c|c|c|}
\hline Núm. & Document & Datació & $3 \mathrm{II}$ & $3 \mathrm{C}$ & $3 \mathrm{PI}$ & 3PS \\
\hline 1 & $\begin{array}{l}\text { Disputació referent als limits } \\
\text { entre Guissona i Ribelles }\end{array}$ & $1036-1079$ & & & $\begin{array}{l}\text { monstre } 2 \\
\text { proclame }\end{array}$ & $\begin{array}{l}\text { jakescha } \\
\text { defenescha } \\
\text { sia }\end{array}$ \\
\hline 2 & Jurament feudal 2 & $1043-1098$ & & & chomanna & \\
\hline 3 & Acords feudals $1-1$ & $1043-1098$ & & & comande & \\
\hline 4 & Acords feudals 1-2 & $1043-1098$ & & & demanda & \\
\hline 5 & Acords feudals 2-3 & mitjan XI & & & & atenda \\
\hline 6 & Jurament feudal de fidelitat & $1047-1098$ & venia & & comanda & \\
\hline 7 & $\begin{array}{l}\text { Greuges de Guitard Isarn, } \\
\text { senyor de Caboet }\end{array}$ & $1080-1095$ & $\begin{array}{l}\text { facia } \\
\text { partia } \\
\text { avia } 3 \\
\text { jachia } \\
\text { ere }\end{array}$ & siria & & sia \\
\hline 8 & Acords feudals 3-5 & $1094-1110$ & & & & faça \\
\hline 9 & Acords feudals 3-6 & 1117 & & & dona & forsfaza \\
\hline 10 & Llibre dels judicis 1 & 1a m. XII & & & $\begin{array}{l}\text { ajunta } \\
\text { sobrepuja } \\
\text { acapta } 2\end{array}$ & $\begin{array}{l}\text { aja } \\
\text { prenda } \\
\text { puxa } \\
\text { sia } 3 \\
\text { divisia } \\
\text { pertenga }\end{array}$ \\
\hline 11 & $\begin{array}{l}\text { Greuges dels homes de Sant } \\
\text { Pere de Graudescales }\end{array}$ & XII & \begin{tabular}{|l} 
faie \\
solie \\
avie 3 \\
ere \\
menave \\
volie 2 \\
\end{tabular} & $\begin{array}{l}\text { fóre } \\
\text { clamarie } 2\end{array}$ & & \\
\hline 12 & $\begin{array}{l}\text { Greuges dels homes } \\
\text { d'Hostafrancs }\end{array}$ & XII & $\begin{array}{l}\text { valie } 3 \\
\text { avie } 2\end{array}$ & & cobre & \\
\hline
\end{tabular}

En els documents dels segles Xi i XII, - $e$ alterna amb-a en textos diferents i també en un mateix text $i$, si en fem una quantificació global —a títol merament orientatiu, bo i sabent que amb tan poques dades el valor dels percentatges és relatiu_, surten 23 formes amb - $e(43 \%)$ i 3 I amb - a (57\%), percentatges que més aviat són compatibles $a m b$ la idea d'una variant originària $a m b-a$ que ha rebut la competència d'una altra d'innovadora $\mathrm{amb}-e$, que no pas amb la hipòtesi d'una única variant nord-occidental amb - e generada des del principi per una llei fonètica regular. A més, la presència de la grafia - $e$ no és equiparable en tots els temps: en l'imperfet d'indicatiu la trobem en 
Mar Massanell i Messalles

Sincretisme i canvi morfològic: evolució de la terminació verbal en -AT en català

I 5 formes de 22; en el condicional, en 3 de 4 ; en el present d'indicatiu, en 5 de I3; en canvi, no hi ha cap forma amb - $e$ entre les is de present de subjuntiu.

Més que l'anàlisi quantitativa global, però, és l'anàlisi qualitativa d'alguns documents el que resulta més orientador. I diem d'alguns, i no de tots, perquè cal tenir en compte que la major part d'aquests textos dóna un nombre molt reduït de formes rellevants, a voltes una de sola, i aquest fet en dificulta la interpretació: per exemple, el document 2 (Jurament feudal 2, I043-I098) proporciona només una forma de tercera persona del present d'indicatiu de la primera conjugació, que va amb - $a$ final (chomanna), i també el document 3 (Acords feudals I-I, IO43-IO98) dóna una sola ocurrència significativa, també de tercera persona del present d'indicatiu de la primera conjugació i del mateix verb, només que, en aquesta ocasió, amb - e final (comande). ${ }^{28}$

Aporten més informació alguns documents en què el nombre de formes rellevants per al nostre estudi s'eleva moderadament, sobretot quan aquestes corresponen a temps verbals diferents. Per això trobem destacable el cas del document I (Disputació referent als limits entre Guissona i Ribelles, I036-1079), en què apareixen sis formes verbals rellevants, tres de present d'indicatiu i tres de present de subjuntiu. Les tres de present d'indicatiu duen - $e$ final (monstre 2, proclame), mentre que les tres de present de subjuntiu duen - $a$ final (jakescha, defenesch $a$, sia). Més enllà d'una simple coincidència, aquestes dades fan pensar en l'entrada de la vocal - $e$ abans en el present d'indicatiu que en el present de subjuntiu, circumstància que dóna suport a un origen morfològic de la vocal $-e$.

Una altra limitació d'aquests primers textos, per als nostres objectius, és l'absència en molts de formes d'imperfet d'indicatiu, que és el temps en el qual hauria començat el canvi, segons la hipòtesi de l'origen morfològic de la - $e$. En trobem només en quatre documents (6, 7, II i I2), que no són justament els més reculats en el temps. El document 6 (Jurament feudal de fidelitat, I047-I098) fa una aportació limitada, amb una sola forma de 3II: venia, amb -a. Resulta força més interessant el document 7 (Greuges de Guitard Isarn, senyor de Caboet, I080-I095), que al costat d'una forma de tercera persona del condicional (siria) i d'una de tercera persona del present de subjuntiu (sia), ambdues amb - $a$, ofereix set mostres d'imperfet d'indicatiu, sis amb - a (facia, partia, avia 3 , jachia) i una amb-e (ere). Aquest fet podria suggerir — tímidament, perquè són poques dades - que la variant amb - e és una innovació iniciada en l'imperfet d'indicatiu. Els documents II i I2, de datació imprecisa (segle XII), forneixen un esplet de formes d'imperfet d'indicatiu amb -e final: així, faie, solie, avie 3, ere, menave, volie 2

28. Notem que la primera grafia (chomanna) reflecteix l'assimilació del grup -ND-, que no queda recollida, en canvi, en la segona (comande). 
són presents als Greuges dels homes de Sant Pere de Graudescales, mentre que valie 3 i avie 2 ocorren als Greuges del homes d'Hostafrancs.

Amb la prudència deguda, atesa la migradesa del corpus, les dades que aporten aquests primers textos del català occidental naixent permeten de fer algunes observacions:

I. Tot i que la diferència entre les variants no és espectacular, la major part de les formes de tercera persona documentades durant els segles XI i XII en textos nord-occidentals acaben amb la grafia $-a$ (3I, un $57 \%$, enfront de 23 amb -e, un $43 \%)$.

2. La terminació -e, però, ja es documenta al segle XI, raó per la qual podem pensar que en la llengua oral s'havia generat abans, atès el decalatge que hi sol haver en la penetració dels fenòmens orals en l'escrit (Martí i Castell 1990: 53). Així, en el document I (Disputació referent als limits entre Guissona $i$ Ribelles, I036-I079), hem recollit les formes de 3 PI monstre 2 i proclame; en el document 3 (Acords feudals I-I, I043-IO98) s'hi llegeix 3 PI comande; en el document 7 (Greuges de Guitard Isarn, senyor de Caboet, I080-1095), hem descobert la forma ere de $3 \mathrm{II}$ —al costat, això sí, de sis formes amb -a.

3. A diferència del que s'esdevé en el present d'indicatiu, en l'imperfet d'indicatiu i en el condicional, no hem trobat en cap dels textos nord-occidentals dels segles XI i XII formes amb - $e$ de tercera persona del present de subjuntiu: per a aquest temps verbal, totes les formes recollides estan grafiades amb $-a$. Malgrat que quinze ocurrències de $3 \mathrm{PS}$ poden semblar poques, cal tenir present que superen les formes de ${ }_{3} \mathrm{PI}$, que són tretze, i que tampoc no queden gaire per sota de les vint-i-dues de 3 II.

4. Tot i que la migradesa de la documentació ens fa ser prudents, i a l'espera de les dades que aportin els documents del segle XIII, val la pena d'assenyalar les correlacions que s'estableixen pel que fa a l'aparició de la terminació - a en diferents temps verbals. Aquestes correlacions, que es poden formular de manera implicativa («si X té $-a$, llavors $Y$ té $-a »)$, són tres i totes són compatibles amb la hipòtesi — tot i que no la demostren-que les formes amb - e es van generar en l'imperfet d'indicatiu, que després es van expandir al condicional $i$ al present d'indicatiu dels verbs de la primera conjugació, i que el darrer temps en el qual van afermar-se és el present de subjuntiu de les conjugacions no primeres ( $3 \mathrm{II} \rightarrow 3 \mathrm{C} \rightarrow 3 \mathrm{PI} \rightarrow 3 \mathrm{PS}$ ):

a. En els documents en què hem trobat la tercera persona de l'imperfet d'indicatiu escrita $a m b-a$ final -0 escrita majoritàriament $a m b-a$ final一, si hi ha formes de tercera persona del condicional, del present d'indicatiu o del present de subjuntiu, aquestes són també amb - $a$, com exemplifica la taula 8. 
Taula 8. Documents en què es compleix la implicació: si 3 II té $-a$, llavors ${ }_{3} \mathrm{C}$, 3 PI i 3 PS tenen $-a$

\begin{tabular}{|l|l|l||c||c|c|c|}
\hline \multicolumn{2}{|c|}{ Document } & Datació & 3II & 3C & 3PI & 3PS \\
\hline 6 & Jurament feudal de fidelitat & $1047-1098$ & venia & & comanda & \\
\hline 7 & $\begin{array}{l}\text { Greuges de Guitard Isarn, senyor } \\
\text { de Caboet }\end{array}$ & $1080-1095$ & facia & siria & & sia \\
& & & $\begin{array}{c}\text { partia } \\
\text { avia (3) } \\
\text { jachia } \\
\text { [ere }\end{array}$ & & & \\
& & & & & \\
\hline
\end{tabular}

b. En els documents en què la tercera persona del condicional és amb - $a$, si hi ha formes de tercera persona [del present d'indicatiu o] del present de subjuntiu, aquestes també són amb - a (serveix com a exemple el document 7 de la taula 8).

c. En els documents en què la tercera persona del present d'indicatiu acaba en $-a$, si hi ha formes de tercera persona del present de subjuntiu, aquestes també acaben en $-a,{ }^{29}$ com exemplifica la taula 9 .

Taula 9. Documents en què es compleix la implicació: si 3 PI té $-a$, llavors 3 PS té $-a$

\begin{tabular}{|r|l|l|l|l|l||c|}
\hline \multicolumn{2}{|c|}{ Document } & Datació & 3II & 3C & 3PI & 3PS \\
\hline 9 & Acords feudals 3-6 & 1117 & & & dona & forsfaza \\
\hline 10 & Llibre dels judicis 1 & 1a m. XII & & & ajunta & aja \\
& & & & & sobrepuja & prenda \\
& & & & acapta (2) & puxa \\
& & & & & sia (3) \\
& & & & & divisia \\
& & & & & & pertenga \\
\hline
\end{tabular}

5. De la mateixa manera, s'estableixen correlacions pel que fa a l'aparició de la terminació - e en diferents temps verbals. Aquestes correlacions, expressables com a implicacions ( «si X té - $e$, llavors Y té -e»), són dues (atès que no hem localitzat encara formes de tercera persona en $-e$ al present de subjuntiu) i són compatibles amb la hipòtesi — tot i que no la demostren-que les formes amb - $e$ es van generar en l'imperfet d'indicatiu, que després es van expandir al condicional i al present d'indicatiu dels verbs de la primera 
conjugació, i que el darrer temps en el qual van introduir-se és el present de subjuntiu de les altres conjugacions $\left(3 \mathrm{II} \rightarrow 3 \mathrm{C} \rightarrow 3 \mathrm{PI} \rightarrow{ }_{3} \mathrm{PS}\right)$ :

a. En els documents en què la tercera persona del present d'indicatiu és amb $-e$, si hi ha formes de tercera persona [del condicional o] de l'imperfet d'indicatiu, aquestes també són amb -e, com exemplifica la taula Io.

Taula Io. Document en què es compleix la implicació: si 3 PI té -e, llavors 3 II [i 3 C] tenen -e

\begin{tabular}{|c|l|c|c|c||c||c|}
\hline \multicolumn{2}{|c|}{ Document } & Datació & 3II & 3C & 3PI & 3PS \\
\hline 12 & Greuges dels homes d'Hostafrancs & segle XII & $\begin{array}{c}\text { valie (3) } \\
\text { avie (2) }\end{array}$ & & cobre & \\
\hline
\end{tabular}

b. En els documents en què la tercera persona del condicional és amb -e, si hi ha formes de tercera persona d'imperfet d'indicatiu, aquestes també són $\mathrm{amb}-e$, com exemplifica la taula II.

Taula II. Document en què es compleix la implicació: si ${ }_{3} \mathrm{C}$ té -e, llavors 3 II té -e

\begin{tabular}{|c|c|c|c|c|c|c|}
\hline \multicolumn{2}{|r|}{ Document } & Datació & $3 \mathrm{II}$ & $3 \mathrm{C}$ & $3 \mathrm{PI}$ & $3 \mathrm{PS}$ \\
\hline 11 & $\begin{array}{l}\text { Greuges dels homes de Sant } \\
\text { Pere de Graudescales }\end{array}$ & segle XII & $\begin{array}{c}\text { faie } \\
\text { solie } \\
\text { avie } 3 \\
\text { ere } \\
\text { menave } \\
\text { volie } 2\end{array}$ & $\begin{array}{c}\text { fóre } \\
\text { clamarie } 2\end{array}$ & & \\
\hline
\end{tabular}

En darrer lloc, volem assenyalar que les formes de tercera persona amb -e final provenen totes de cinc textos de la societat feudal: una disputació (doc. I), un acord feudal (doc. 3) i tres greuges (doc. 7, II i I2). No n'hem trobat cap en el document Io, el fragment de la traducció del Liber iudiciorum, de caràcter més formal i culte. Aquest fet pot no significar res: al cap i a la fi, també hi ha sis textos de la societat feudal en què només apareix la terminació amb - $a$ (doc. 2, 4, 5, 6, 8 i 9). També podria indicar, però, que la terminació amb -e és una innovació $i$, com a tal, es percep com una forma menys adequada per a la llengua formal. Novament, el fet de no disposar d'un corpus més ampli impedeix asseverar i només permet suggerir, però l'absència de la terminació - $e$ en un text culte és més beneficiosa a la hipòtesi que la - $e$ és una innovació de tipus morfològic que va desplaçar la $-a$, que no pas a la hipòtesi de la - $e$ com a forma originària generada per evolució fonètica regular. 
Un cop fetes aquestes constatacions, i vistes les limitacions dels primers textos dels segles XI i XII a causa de la brevetat i del poc nombre de formes rellevants que contenen, considerem que és clau l'anàlisi de les Homilies d'Organyà, de I204, el primer text d'una certa extensió del català nord-occidental (i del català en general). D'una banda, és el primer text en què trobem exemples de tercera persona de tots els temps verbals que buidem (PI, II, C i PS). De l'altra, passem d'un màxim d'una dotzena de formes rellevants en els textos precedents a III formes rellevants a les Homilies d'Organyà. Convé, doncs, que analitzem amb detall aquesta obra.

\subsection{Les Homilies d'Organyà}

El primer que cal assenyalar, en enfrontar-nos a les dades de les Homilies, és la coexistència de formes amb les variants $-a \mathrm{i}-e$, recollides a la taula $\mathrm{I} 2$, amb una distribució que considerem significativa.

Taula I2. Buidatge de formes de tercera persona de l'imperfet d'indicatiu (3II), del condicional $\left.{ }_{3} \mathrm{C}\right)$, del present d'indicatiu (3PI) de la primera conjugació i del present de subjuntiu (3$\left.{ }_{3} \mathrm{PS}\right)$ de les conjugacions no primeres, corresponent a les Homilies d'Organyà (document I3)

\begin{tabular}{|c|c|c|c|c|c|c|c|}
\hline \multicolumn{8}{|c|}{ Homilies d'Organyà (1204) } \\
\hline \multicolumn{2}{|c|}{$3 \mathrm{II}$} & \multicolumn{2}{|c|}{$3 \mathrm{C}$} & \multicolumn{2}{|c|}{ 3PI } & \multicolumn{2}{|c|}{ 3PS } \\
\hline$a$ & $e$ & $a$ & $e$ & $a$ & $e$ & $a$ & $e$ \\
\hline $\begin{array}{l}\text { semenava } \\
\text { avia } 7 \\
\text { queria } \\
\text { venia } \\
\text { volia } 5 \\
\text { era } 2 \\
\text { prometia } \\
\text { menava } \\
\text { clamava } \\
\text { garia } \\
\text { pregava }\end{array}$ & $\begin{array}{l}\text { parlave } \\
\text { ere } 14 \\
\text { avie } \\
\text { dezie } 2 \\
\text { anave } 2 \\
\text { dizie } \\
\text { acaptave } \\
\text { vevie } \\
\text { pasave } \\
\text { cridave } 2 \\
\text { pregave } \\
\text { clamave } 3 \\
\text { fazie } \\
\text { estave } \\
\text { gitave } \\
\text { adorave } \\
\text { aproxmave } \\
\text { devie }\end{array}$ & $\begin{array}{l}\text { redebria } \\
\text { perdonaria } \\
\text { faria } 3 \\
\text { daria }\end{array}$ & tenrie & $\begin{array}{l}\text { sona } \\
\text { treballa } \\
\text { gia } \\
\text { perdona } \\
\text { apela } 4 \\
\text { dóna } 2 \\
\text { penssa } \\
\text { demostra } 4 \\
\text { porta } 3 \\
\text { torna } \\
\text { tanca } \\
\text { laxa } \\
\text { aferma } \\
\text { acorda } \\
\text { manda } \\
\text { mostra } 3 \\
\text { significa }\end{array}$ & $\begin{array}{l}\text { cuide } \\
\text { engane } \\
\text { cese }\end{array}$ & $\begin{array}{l}\text { tola } 2 \\
\text { sia } \\
\text { pusca } \\
\text { traga } \\
\text { prena } \\
\text { faza } \\
\text { aja } 5 \\
\text { vinga }\end{array}$ & $\begin{array}{l}\text { segesqe } \\
\text { parcesqe }\end{array}$ \\
\hline
\end{tabular}


La primera evidència és el comportament diferenciat entre l'imperfet d'indicatiu i la resta de temps verbals: $62 \%$ de formes de tercera persona amb -e, enfront de $38 \%$ $\mathrm{amb}-a$, mentre que el condicional, el present d'indicatiu i el present de subjuntiu mostren una situació similar entre si i ben diferent de la de l'imperfet d'indicatiu, ja que es troba un $86 \%$ de formes amb - $a$ en el condicional, un $90 \%$ en el present d'indicatiu i un $87 \%$ en el present de subjuntiu, com sintetitza la taula I3.

Taula 13. Quantificació del buidatge de les formes de tercera persona de l'imperfet d'indicatiu, el condicional, el present d'indicatiu de la primera conjugació i el present de subjuntiu de les conjugacions no primeres, extretes de les Homilies d'Organyà

\begin{tabular}{|r|r|r|r|r|r|r|r|r|}
\hline \multirow{2}{*}{$\begin{array}{c}\text { Homilies } \\
\text { d'Organyà } \\
(1204)\end{array}$} & \multicolumn{2}{|c|}{$\begin{array}{c}\text { imperfet } \\
\text { d'indicatiu }\end{array}$} & \multicolumn{2}{|c|}{ condicional } & \multicolumn{2}{c|}{$\begin{array}{c}\text { present } \\
\text { d'indicatiu }\end{array}$} & \multicolumn{2}{c|}{$\begin{array}{c}\text { present } \\
\text { de subjuntiu }\end{array}$} \\
\cline { 2 - 9 } & nombre & $\%$ & nombre & $\%$ & nombre & $\%$ & nombre & $\%$ \\
\hline grafia $a$ & 22 & $38 \%$ & 6 & $\mathbf{8 6 \%}$ & 28 & $\mathbf{9 0 \%}$ & 13 & $\mathbf{8 7} \%$ \\
\hline grafia $e$ & 36 & $\mathbf{6 2} \%$ & 1 & $14 \%$ & 3 & $10 \%$ & 2 & $13 \%$ \\
\hline
\end{tabular}

Una diferència percentual tan elevada no sembla que pugui ser casual i abona la hipòtesi de l'origen morfològic de les formes de tercera persona acabades en -e. Es partiria de formes amb - a final, obtingudes per evolució fonètica (-AT >-a), que anirien sent substituïdes per formes amb $-e$, generades per evitar el sincretisme entre la primera persona i la tercera. I on s'haurien originat aquestes formes? En l'imperfet d'indicatiu: és el que esperàvem i és la hipòtesi que troba suport documental a partir del buidatge de les Homilies. En formular-la, ja hem exposat que el present d'indicatiu no patia sincretisme i, per tant, no podia ser el motor d'un canvi que perseguia evitar-lo; el condicional, que sí que és sincrètic, és un temps poc emprat (a les Homilies d'Organyà, 7 formes de $3 \mathrm{C}$ enfront de 58 de $3 \mathrm{II}$ ) i és previsible, doncs, que en la innovació vagi a remolc d'un temps més freqüent, i el present de subjuntiu pertany a un mode marcat i, per aquesta raó, admet millor el sincretisme.

Fixem-nos, però, que el buidatge de les Homilies permet d'afinar més. Si destriem les formes de tercera persona d'imperfet d'indicatiu per conjugacions, descobrim un nou salt de percentatges que tampoc no sembla atribuïble a la casualitat (vegeu la taula I4). A la primera conjugació, la que acull més verbs, el domini de la -e a la tercera persona és màxim: Is formes amb $e(75 \%)$, enfront de 5 formes amb $a(25 \%)$. En canvi, en les conjugacions no primeres la -e presenta una situació menys consolidada: 2 I formes amb $e(55 \%)$, per 17 formes amb $a(45 \%)$. Per a evitar la sorpresa que pugui causar-li al lector el fet que la conjugació «freqüent» aplegui 20 formes i les

Caplletra 61 (Tardor, 2016), pp. 165-209 
altres en sumin 38, ens afanyem a dir que aquesta xifra inclou els verbs ésser i haver, ambdós empradíssims en català antic com a verbs auxiliars o lèxics. Si restem les 24 ocurrències que acumulen entre tots dos (I6 ésser i 8 haver), el panorama sembla més raonable: 20 formes de 3 II corresponents a la primera conjugació i I4 de corresponents a les conjugacions no primeres. D’aquestes, 6 són amb -e (43\%) i 8 són amb a (57\%): es confirma, per tant, el contrast amb els percentatges de la primera conjugació $(75 \%$ $\mathrm{amb}-e, 25 \% \mathrm{amb}-a)$. Aquesta circumstància fa pensar que el canvi va sorgir concretament en l'imperfet d'indicatiu de la primera conjugació, fet que no sorprèn si tenim en compte que és la conjugació amb un major nombre de verbs i l'única productiva al costat del submodel incoatiu i, per tant, és la més procliu a admetre innovacions: «En la majoria de casos, les innovacions de la primera conjugació — la més productiva, regular $i$, per tant, estable - s'han generalitzat en les altres conjugacions - no productives, més irregulars i menys estables» (Pérez Saldanya 1998: 168).

Taula I4. Quantificació del buidatge de les formes de tercera persona d'imperfet d'indicatiu extretes de les Homilies d'Organyà, en funció de la pertinença del verb a la primera conjugació o a les conjugacions no primeres, amb segregació dels resultats dels verbs ésser i haver

\begin{tabular}{|c|c|c|c|c|c|c|c|c|}
\hline \multirow{4}{*}{$\begin{array}{c}\text { Homilies } \\
\text { d'Organyà } \\
(1204)\end{array}$} & \multicolumn{8}{|c|}{ imperfet d'indicatiu } \\
\hline & \multirow{2}{*}{\multicolumn{2}{|c|}{$\begin{array}{l}\text { 1a conjugació } \\
\text {-ava /-ave }\end{array}$}} & \multicolumn{6}{|c|}{ conjugacions no primeres } \\
\hline & & & \multicolumn{2}{|c|}{$\begin{array}{c}\text { ésser } \\
\text { era / ere }\end{array}$} & \multicolumn{2}{|c|}{$\begin{array}{l}\text { resta de verbs } \\
\quad-i a /-i e\end{array}$} & \multicolumn{2}{|c|}{$\begin{array}{c}\text { haver } \\
\text { avia / avie }\end{array}$} \\
\hline & nombre & $\%$ & nombre & $\%$ & nombre & $\%$ & nombre & $\%$ \\
\hline grafia $a$ & 5 & $25 \%$ & 2 & $12,5 \%$ & 8 & $57 \%$ & 7 & $87,5 \%$ \\
\hline \multirow[t]{2}{*}{ grafia $e$} & 15 & $75 \%$ & 14 & $87,5 \%$ & 6 & $43 \%$ & 1 & $12,5 \%$ \\
\hline & 20 & & 16 & & 14 & & 8 & \\
\hline
\end{tabular}

No podem deixar de banda el cas dels verbs haver i ésser, que hem segregat en el paràgraf anterior. Les xifres poden resultar curioses: avia té 7 ocurrències, davant de només I d'avie ( $87,5 \%$ enfront de I2,5\%); inversament, ere es recull en I4 ocasions, per només 2 d'era (els percentatges es capgiren: I2,5\% enfront de 87,5\%). Pot haver-hi alguna explicació? Se'ns acut que l'imperfet d'indicatiu avia té la mateixa estructura i la mateixa forma que els imperfets d'indicatiu regulars de les conjugacions no primeres (avia com batia: -ia): per tant, la introducció de la terminació - e correspondria a la segona fase del procés, l'expansió des de l'imperfet d'indicatiu de la primera conjugació cap a l'imperfet d'indicatiu de les altres; que mostri un estadi de predomini de $-a$ s'adiu amb la resta de dades d'aquest testimoni. En canvi, era és un imperfet 
d'indicatiu irregular, que no respon a la terminació de les conjugacions no primeres i que té una estructura que recorda la desinència dels imperfets d'indicatiu de la primera (era com [cant]ava: 'VCV): aquests fets en podrien haver afavorit una evolució més ràpida al marge de la resta de verbs de la conjugació que li correspon.

D'altra banda, la $e$ tònica d'era fa temptador de pensar en una metafonia com a coadjuvant de la transformació d'era en ere. I ens permetem de recordar — per si no és casual— que el document 7 (Greuges de Guitard Isarn, senyor de Caboet, I080-1095) ofereix set mostres d'imperfet d'indicatiu, totes de verbs de conjugacions no primeres, sis amb -a (facia, partia, avia 3, jachia) i una amb -e, que justament és ere. A més, la suposició que la vocal $e$ tònica hi ha afavorit la penetració més ràpida de la - $e$ de tercera persona rep suport en unes altres dades procedents de les Homilies d'Organyà. Si observem la llista de is formes de tercera persona del present de subjuntiu, se'ns farà evident que només dues han adoptat la -e final i que són, justament, les dues que corresponen al submodel incoatiu i que presenten, per aquesta raó, l'increment -esc-, també amb $e$ tònica: segesqe, parcesqe, en contrast amb tola 2, sia, pusca, traga, prena, faza, aja 5, vinga.

Si deixem l'imperfet d'indicatiu i centrem l'atenció en la resta de temps afectats, veurem com els percentatges de distribució de les dues variants, $-a \mathrm{i}-e$, entre les formes de tercera persona del condicional, del present d'indicatiu i del present de subjuntiu són molt iguals i indiquen una penetració tímida de la terminació amb -e ( $\mathrm{I} 4 \%$ en el C, IO\% en el PI, I3\% en el PS), que no permet aventurar cap a quin temps va propagar-se primer partint de l'imperfet d'indicatiu (si no és que ho va fer cap a tots alhora, cosa que no esperem per les diferències entre els tres temps afectats, que ja hem remarcat en la formulació de la hipòtesi). Tanmateix, hem de recordar que, pel que fa al present de subjuntiu, només un submodel, el dels verbs incoatius, ha adoptat la -e: en la resta de casos, la tercera persona va invariablement amb - $a$. Aquesta situació suposa un canvi respecte dels segles anteriors, en què només trobàvem formes de $3 \mathrm{PS}$ amb $-a$. I això inclou les ocurrències de verbs del submodel incoatiu, que localitzàvem en el document I (Disputació referent als limits entre Guissona i Ribelles, I036-I079) -i que reproduïm en la taula comparativa I5-, en el qual recordem que també ocorrien formes de $3 \mathrm{PI}$, i aquestes sí que duien -e final. 
Mar Massanell i Messalles

Sincretisme i canvi morfològic: evolució de la terminació verbal en -AT en català

Taula I5. Comparació de les formes de 3 PS [-Ia conj.] obtingudes en un document del segle XI, la Disputació referent als limits entre Guissona i Ribelles (I036-IO79), i a les Homilies d'Organyà (I204)

\begin{tabular}{|c|c|c|c|c|}
\cline { 2 - 5 } \multicolumn{1}{c|}{} & \multicolumn{2}{c|}{$\begin{array}{c}\text { Disputació referent als limits entre Guissona i... } \\
(1036-1079)\end{array}$} & \multicolumn{2}{c|}{$\begin{array}{c}\text { Homilies d'Organyà } \\
\text { (1204) }\end{array}$} \\
\cline { 2 - 5 } \multicolumn{1}{c|}{} & $\begin{array}{c}\text { 3PS } \\
\text { [altres] }\end{array}$ & $\begin{array}{c}\text { 3PS } \\
\text { [incoatius: -esc-] }\end{array}$ & $\begin{array}{c}\text { 3PS } \\
\text { [altres] }\end{array}$ & $\begin{array}{c}\text { 3PS } \\
\text { [incoatius: -esc-] }\end{array}$ \\
\hline$-a$ & sia & jakescha, defenescha & $\begin{array}{c}\text { tola 2, sia, pusca, traga, } \\
\text { prena, faza, aja 5, vinga }\end{array}$ & \\
\hline$-e$ & & & & segesqe, parcesqe \\
\hline
\end{tabular}

Sembla, segons aquestes dades, que el submodel incoatiu va admetre la innovació de la variant $-e$ de tercera persona abans que la resta de formes de subjuntiu, pensem que amb ajuda de la $e$ tònica del segment -esc-, que hauria afavorit l'harmonia vocàlica. Recordem que no és estrany que fets fonètics i fets morfològics s'entrellacin en les evolucions de les formes verbals: en tenim un exemple, ben establert per Coromines (197I), en l'origen de la terminació -o de primera persona del present d'indicatiu, sorgida per assimilació en verbs amb vocal velar tònica (plore > ploro, mostre $>$ mostro) i generalitzada després a la resta amb valor morfològic. Fora del submodel conjugacional incoatiu, el present de subjuntiu mantindria la $-a$ amb fermesa i no presentaria les alternances que sí que mostren, moderadament, el condicional, amb un $\mathrm{I} 4 \%$ de formes amb -e (tenrie al costat de redebria), i el present d'indicatiu, amb un Io\% (cuide al costat d'acorda).

El buidatge de les Homilies d'Organyà, doncs, proporciona suport documental a la hipòtesi de l'origen morfològic de la -e de tercera persona $\mathrm{i}$, a més, permet d'afinar-la. Les dades que n'hem extret suggereixen que el canvi cap a la terminació - e s'hauria iniciat, per a defugir el sincretisme de persona, en l'imperfet d'indicatiu, concretament en el de la primera conjugació (III cantava, 3II cantava $\rightarrow$ III cantava, 3II cantave), la que aplega més verbs i l'única productiva juntament amb el submodel incoatiu, i després s'hauria estès a l'imperfet d'indicatiu de les conjugacions no primeres (III batia, 3 II batia $\rightarrow$ III batia, 3 II batie), amb un avanç molt ràpid en el cas de l'imperfet irregular ere, afavorit per metafonia.

A partir de les formes d'imperfet d'indicatiu, el model antisincrètic s'hauria expandit a un temps menys freqüent — però que presentava el mateix conflicte d'opacitat entre la primera persona i la tercera-, el condicional ( $\mathrm{IC}$ cantaria, ${ }_{3} \mathrm{C}$ cantaria $\rightarrow \mathrm{IC}$ cantaria, ${ }_{3} \mathrm{C}$ cantarie i $\mathrm{IC}$ batria, ${ }_{3} \mathrm{C}$ batria $\rightarrow \mathrm{IC}$ batria, ${ }_{3} \mathrm{C}$ batrie). La consolidació de la -e de tercera persona a l'imperfet d'indicatiu, i la seva expansió cap al condicional, 
hauria afectat el present d'indicatiu de l'única conjugació amb desinència vocàlica a la tercera persona (3PI canta) i, malgrat l'absència de sincretisme respecte de la forma de primera persona (IPI cant), la tendència a l'homogeneïtat paradigmàtica n'hauria afavorit la transformació (IPI cant, 3 PI canta $\rightarrow \mathrm{IPI}$ cant, $3 \mathrm{PI}$ cante), atès que la forma amb -e és més congruent en el conjunt de paradigmes del sistema (3II cantave, ${ }_{3} \mathrm{C}$ cantarie $\rightarrow 3$ PI cante: totes les formes de tercera persona amb -e) i, a més, incrementa la uniformitat intraparadigmàtica, ja que en la resta de persones del present d'indicatiu amb vocal àtona aquesta vocal és $e\left(2 \mathrm{PI}\right.$ cantes, $6 \mathrm{PI}$ canten $\rightarrow{ }_{3} \mathrm{PI}$ cante).$^{30}$

Finalment, la terminació amb - es'obriria pas en el present de subjuntiu de les conjugacions no primeres, amb desinència vocàlica a la primera persona i la tercera, el qual, malgrat el sincretisme que presentava, era menys propens al canvi, atès que els modes més marcats, com el subjuntiu, suporten millor les coincidències formals. Cal tenir present que les formes que expressen categories marcades presenten una freqüència textual menor que les no marcades i són menys centrals que aquestes en el procés comunicatiu (Wheeler 2007 [1993b]: I02): s'entén, doncs, que resulti menys problemàtic que una forma marcada no sigui unívoca i que, per aquesta raó, les confusions formals se suportin millor en contextos marcats que no pas quan afecten formes més bàsiques del sistema. A partir del submodel incoatiu, però, el segment -esc- del qual, amb $e$ tònica, afavoria la implantació del canvi per metafonia (seguesque), es va arribar a la darrera de les transformacions de la cadena (IPS [que jo] bata, 3 PS [que ell] bata $\rightarrow$ IPS [que jo] bata, 3PS [que ell] bate), no recollida encara a les Homilies. Sintetitzem els diferents passos del canvi en la taula 16.

30. Estrictament, les Homilies d'Organyà donen suport documental a les dues baules extremes de la cadena evolutiva proposada en la hipòtesi $(3 \mathrm{II} \rightarrow 3 \mathrm{C} \rightarrow 3 \mathrm{PI} \rightarrow 3 \mathrm{PS})$ : així, l'imperfet d'indicatiu s'hi mostra clarament com el focus originari de la transformació i el present de subjuntiu s'hi revela, també clarament, com el darrer temps que accepta el canvi. Igualment resulta evident que el condicional i el present d'indicatiu es troben en el segment mitjà de la cadena, però les dades no permeten d'afirmar si l'ordre precís de la mutació és realment ${ }_{3} \mathrm{C} \rightarrow 3$ PI (primer en el condicional i després en el present d'indicatiu), com hem suposat argumentadament en la formulació de la hipòtesi, o bé ${ }_{3} \mathrm{PI} \rightarrow{ }_{3} \mathrm{C}$ (primer en el present d'indicatiu i després en el condicional) o $3 \mathrm{C} / 3 \mathrm{PI}$ (a tots dos temps alhora). Sigui com sigui, els arguments que justifiquen l'èxit de la mutació en aquests dos temps verbals són els que hem exposat i no resultarien contradits si noves dades aconsellessin de modificar l'ordenació de les dues baules centrals de la cadena. 
Taula I6. Esquema de la propagació de les formes de tercera persona en - $e$ a partir de l'imperfet d'indicatiu dels verbs de la primera conjugació fins arribar al present de subjuntiu de les conjugacions no primeres

\begin{tabular}{|c|c|c|c|c|c|c|}
\hline \multirow[b]{2}{*}{ 1a conjugació } & 1a etapa & & 2a etapa & \multirow[b]{2}{*}{$\rightarrow$} & 3a etapa & \multirow[t]{3}{*}{ 4a etapa } \\
\hline & $\begin{array}{c}\text { Imperfet } \\
\text { d'indicatiu } \\
\text { [1 conj.] } \\
\text { cantave }\end{array}$ & $\rightarrow$ & $\begin{array}{l}\text { Condicional } \\
\text { [1 conj. }] \\
\text { cantarie }\end{array}$ & & $\begin{array}{c}\text { Present } \\
\text { d'indicatiu } \\
{[1 \text { conj. }]} \\
\text { cante } \\
\uparrow \\
2 \mathrm{PI}-e s, 6 \mathrm{PI}-e n \\
\text { cantes, canten }\end{array}$ & \\
\hline & $\downarrow$ & & $\downarrow$ & & & \\
\hline $\begin{array}{l}\text { conjugacions } \\
\text { no primeres }\end{array}$ & $\begin{array}{c}\text { Imperfet } \\
\text { d'indicatiu } \\
{[-1 \text { conj.] }} \\
\text { (ésser) } \\
\text { ere } \\
\downarrow \\
\text { Imperfet } \\
\text { d'indicatiu } \\
\text { [-1 conj.] } \\
\text { (la resta) } \\
\text { batie }\end{array}$ & $\rightarrow$ & $\begin{array}{c}\text { Condicional } \\
\text { [-1 conj.] } \\
\text { batrie }\end{array}$ & & $\rightarrow$ & $\begin{array}{c}\text { Present de } \\
\text { subjuntiu } \\
{[-1 \text { conj.] }} \\
(- \text { esc-) } \\
\text { seguesque } \\
\downarrow \\
\text { Present de } \\
\text { subjuntiu } \\
\text { [-1 conj.] } \\
\text { (la resta) } \\
\text { bate }\end{array}$ \\
\hline
\end{tabular}

\subsection{LA RESTA DE TEXTOS DEL SEGLE XIII}

Un cop analitzades les Homilies d'Organyà (I204), novament topem amb la dificultat de l'extensió dels textos: la resta de documents del segle XIII (numerats del I4 al 30) tornen a ser curts i contenen nombres reduïts o moderats de formes rellevants — que apleguem a la taula I7-, amb la circumstància que no n'hi ha cap que contingui formes de tercera persona dels quatre temps verbals que estudiem (PI, II, C, PS), com també s'esdevenia en els textos dels segles XI i XII. 
Taula 17. Buidatge de formes de tercera persona del l'imperfet d'indicatiu (3II), del condicional $\left.{ }_{3} \mathrm{C}\right)$, del present d'indicatiu (3PI) de la primera conjugació i del present de subjuntiu (3PS) de les conjugacions no primeres, corresponent als textos del corpus datats al segle XIII (documents i4 a 30), amb l'excepció de les Homilies d'Organyà, que hem tractat de manera isolada

\begin{tabular}{|c|c|c|c|c|c|c|}
\hline Núm. & Document & Datació & $3 \mathrm{II}$ & $3 \mathrm{C}$ & $3 \mathrm{PI}$ & 3PS \\
\hline 14 & $\begin{array}{l}\text { Rendició del castell de } \\
\text { Llorenç }\end{array}$ & 1211 & & & & \begin{tabular}{|l} 
sia 2 \\
aja \\
sàpia \\
pusca \\
\end{tabular} \\
\hline 15 & $\begin{array}{l}\text { Donació d'oliverars } \\
\text { per part de Ramona } \\
\text { de Solans i altres }\end{array}$ & 1241 & & & afronte 3 & \\
\hline 16 & $\begin{array}{l}\text { Queixes de l'església } \\
\text { de Puigfalconer }\end{array}$ & 1242 & \begin{tabular}{|l|} 
avie 3 \\
devie 2 \\
tenie \\
ere \\
parie \\
tolie \\
podie
\end{tabular} & $\begin{array}{l}\text { darie } \\
\text { fermarie } \\
\text { posarie }\end{array}$ & & sie 2 \\
\hline 17 & $\begin{array}{l}\text { Controvèrsies a } \\
\text { l'entorn de l'església } \\
\text { d'Organyà-1 }\end{array}$ & 1243 & \begin{tabular}{|l} 
era \\
ere 3 \\
avie 3
\end{tabular} & & $\begin{array}{l}\text { atorga } \\
\text { demanne }\end{array}$ & sie 2 \\
\hline 18 & $\begin{array}{l}\text { Controvèrsies a } \\
\text { l'entorn de l'església } \\
\text { d'Organyà-2 }\end{array}$ & $1243-1250$ & & & $\begin{array}{l}\text { demanne } \\
\text { nege } \\
\text { condemne }\end{array}$ & sie \\
\hline 19 & $\begin{array}{l}\text { Lletres en català als } \\
\text { bisbes d'Urgell } 1\end{array}$ & 1244 & $\begin{array}{l}\text { era } \\
\text { esdevenia }\end{array}$ & & & $\begin{array}{l}\text { sia } 2 \\
\text { volla } \\
\text { aja }\end{array}$ \\
\hline 20 & $\begin{array}{l}\text { Donació de terres al } \\
\text { Pallars per part de A. } \\
\text { Assalid }\end{array}$ & 1248 & & & & faza \\
\hline 21 & $\begin{array}{l}\text { Disputació entre } \\
\text { R. Maasen i Ferrer } \\
\text { d'Escales }\end{array}$ & $1250-1255$ & \begin{tabular}{|l|} 
tenia \\
avia 2 \\
possedia \\
devia \\
\end{tabular} & & $\begin{array}{l}\text { clama } 3 \\
\text { demana } 3 \\
\text { prega } 3\end{array}$ & $\begin{array}{l}\text { sia } 2 \\
\text { faça }\end{array}$ \\
\hline 22 & $\begin{array}{l}\text { Lletres en català als } \\
\text { bisbes d'Urgell 2-IV }\end{array}$ & $1230-1255$ & & & & $\begin{array}{l}\text { pusche } \\
\text { tinge }\end{array}$ \\
\hline 23 & $\begin{array}{l}\text { Lletres en català als } \\
\text { bisbes d'Urgell 2-VI }\end{array}$ & c. 1251 & $\begin{array}{l}\text { ere } 2 \\
\text { avie } 2\end{array}$ & & $\begin{array}{l}\text { fale } \\
\text { ajude } \\
\text { renge } \\
\text { dóne } \\
\end{array}$ & estie \\
\hline
\end{tabular}


Mar Massanell i Messalles

Sincretisme i canvi morfològic: evolució de la terminació verbal en -AT en català

\begin{tabular}{|c|c|c|c|c|c|c|}
\hline 24 & \begin{tabular}{|l|} 
Lletres en català als \\
bisbes d'Urgell 3-VII
\end{tabular} & $1257-1269$ & & & & aje \\
\hline 25 & $\begin{array}{l}\text { Lletres en català } \\
\text { als bisbes d'Urgell } \\
3 \text {-VIII }\end{array}$ & $1257-1269$ & esdevenie & & trigue & \\
\hline 26 & $\begin{array}{l}\text { Lletres en català als } \\
\text { bisbes d'Urgell 3-XII }\end{array}$ & $1257-1269$ & & volrie & & \\
\hline 27 & \begin{tabular}{|l|} 
Lletres en català als \\
bisbes d'Urgell 3-XIII
\end{tabular} & $1257-1269$ & & & & vage \\
\hline 28 & $\begin{array}{l}\text { Cartes al bisbe } \\
\text { d'Urgell-1 }\end{array}$ & 1259 & & & pledege & valga \\
\hline 29 & $\begin{array}{l}\text { Cartes al bisbe } \\
\text { d'Urgell-2 }\end{array}$ & $1257-1269$ & $\begin{array}{l}\text { feve } \\
\text { ere }\end{array}$ & & demane 2 & sie \\
\hline 30 & $\begin{array}{l}\text { La venda del castell } \\
\text { d'Altés }\end{array}$ & 1288 & morie & & & \begin{tabular}{|l|} 
faze \\
age 4 \\
absolve \\
defenesche \\
pusche \\
sie 5 \\
pertange \\
entene \\
vuyle \\
\end{tabular} \\
\hline
\end{tabular}

Si comencem fent un còmput global de formes, es posa de manifest la tendència al capgirament de la variant prioritària: als segles XI i XII havíem recollit 54 formes rellevants, 3I amb - $a(57 \%)$ i $23 \mathrm{amb}-e(43 \%)$, mentre que al segle XIII hem recollit (Homilies d'Organyà a banda) IO2 formes, $32 \mathrm{amb}-a$ (31\%) i $70 \mathrm{amb}-e$ (69\%). Aquestes dades serveixen, simplement, per a assenyalar una tendència, tot i que el seu valor és relatiu: els textos, malgrat que tots són força breus, tenen extensions desiguals i aporten nombres diversos de formes, les quals, a més, poden correspondre a temps verbals diferents. Com ja hem fet per al corpus dels segles XI i XII, doncs, més que atendre a les dades quantitatives globals haurem de centrar-nos en l'anàlisi qualitativa d'alguns textos que resulten més valuosos, sigui pel nombre d'ocurrències que aporten, sigui per la diversitat de temps que hi trobem. Els dos més destacats són els documents 7 i 28, pel fet que contenen formes amb - $a$ i amb - $e$.

En el primer cas (Controvèrsies a l'entorn de l'església d'Organyà-I, I243), observem que la variant amb - $e$ ja ha penetrat en tots els temps verbals que hi apareixen: en l'imperfet d'indicatiu, ere 3, avie 3; en el present d'indicatiu, demanne, i en el present de subjuntiu, sie 2 (tot i que queden restes de les formes amb - a: $3 \mathrm{II}$ era i $3 \mathrm{PI}$ atorga). En el segon (Cartes al bisbe d'Urgell-I, I259), trobem un altre exemple de document 
en què el present d'indicatiu té la terminació - $e$ (3PI pledege), mentre que el present de subjuntiu mostra - $a$ (3PS valga), com ja havíem assenyalat per al document I dels segles XI i XII.

Val a dir que cap dels textos del segle XIII no contradiu les correlacions que ja havíem establert als segles XI i XII pel que fa a l'aparició de la terminació - $a$ a la tercera persona dels diversos temps verbals estudiats, i que formulem en forma d'implicacions:

a. si 3 II té $-a$, llavors ${ }_{3} \mathrm{C},{ }_{3} \mathrm{PI}$ i 3 PS tenen $-a$;

b. si $3 \mathrm{C}$ té $-a$, llavors $3 \mathrm{PI}$ i $3 \mathrm{PS}$ tenen $-a$;

c. si 3 PI té $-a$, llavors 3 PS té $-a$.

De la mateixa manera, es mantenen les correlacions que ja havíem assenyalat pel que fa a l'aparició de la terminació - e en els diversos temps, amb la novetat que la troballa de formes de tercera persona del present de subjuntiu amb - $e$ ha permès d'afegir la correlació que faltava (que és la que porta la lletra a i que exemplifiquem a la taula 18$)$ :

a. si ${ }_{3} \mathrm{PS}$ té $-e$, llavors ${ }_{3} \mathrm{II},{ }_{3} \mathrm{C}$ i 3 PI tenen $-e$;

Taula I8. Alguns dels documents en què es compleix la implicació:

si 3 PS té $-e$, llavors 3 II, 3 C i 3 PI tenen -e

\begin{tabular}{|c|c|c|c|c|c|c|}
\hline \multicolumn{2}{|r|}{ Document } & Datació & $3 \mathrm{II}$ & $3 \mathrm{C}$ & $3 \mathrm{PI}$ & $3 \mathrm{PS}$ \\
\hline 16 & $\begin{array}{l}\text { Queixes de l'església de } \\
\text { Puigfalconer }\end{array}$ & 1242 & $\begin{array}{c}\text { avie } 3 \\
\text { devie } 2 \\
\text { tenie } \\
\text { ere } \\
\text { parie } \\
\text { tolie } \\
\text { podie }\end{array}$ & $\begin{array}{c}\text { darie } \\
\text { fermarie } \\
\text { posarie }\end{array}$ & & sie 2 \\
\hline 29 & Cartes al bisbe d'Urgell-2 & $1257-1269$ & $\begin{array}{l}\text { feve } \\
\text { ere }\end{array}$ & & demane 2 & sie \\
\hline
\end{tabular}

b. si $3 \mathrm{PI}$ té $-e$, llavors $3 \mathrm{II}$ i $3 \mathrm{C}$ tenen $-e$;

c. si $3 \mathrm{C}$ té $-e$, llavors 3 II té $-e$.

Aquestes correlacions, atesos els pocs documents amb què comptem, per si soles no demostren res, però són les esperables si la hipòtesi de l'origen morfològic de la terminació - $e$ de tercera persona, i la seqüència expansiva que comporta, són certes, segons representem a la taula i9 per a la terminació - a i a la 20 per a la terminació - $e$ : 
Mar Massanell i Messalles

Sincretisme i canvi morfològic: evolució de la terminació verbal en -AT en català

Taula 19. Seqüència expansiva de la terminació - $e$ a partir de l'imperfet d'indicatiu i lligam amb les implicacions sobre l'aparició de la terminació - $a$ en els diversos temps verbals

\begin{tabular}{|c|c|c|c|c|c|c|}
\hline $3 \mathrm{II}$ & $\rightarrow$ & $3 \mathrm{C}$ & $\rightarrow$ & $3 \mathrm{PI}$ & $\rightarrow$ & $3 \mathrm{PS}$ \\
\hline $\mathrm{Si}-a \ldots$ & & $\ldots$..llavors $-a$ & & ...llavors $-a$ & & ...llavors $-a$ \\
\hline \multirow{2}{*}{ 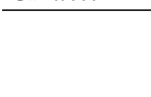 } & & Si $-a \ldots$ & & ...llavors $-a$ & & ...llavors $-a$ \\
\hline & & & & $S i-a \ldots$ & & ...llavors $-a$ \\
\hline
\end{tabular}

Taula 20. Seqüència expansiva de la terminació -e a partir de l'imperfet d'indicatiu i lligam amb les implicacions sobre l'aparició de la terminació -e en els diversos temps verbals

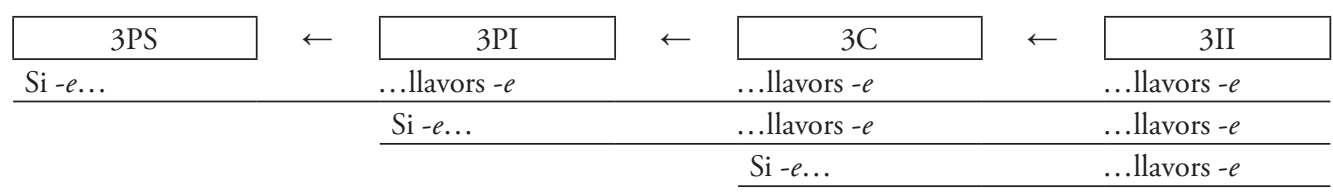

També és interessant de fixar-se en el nombre de textos que presenten una única variant a la terminació de tercera persona, sigui $-a$ o $-e$, tot i que el valor d'aquesta circumstància no sempre és equiparable, pel nombre divers d'ocurrències dels documents, que pot anar des d'una en els casos més migrats (doc. 20, 24, 26 i 27) fins a disset en els més productius (doc. 2I i 30). La visió general que proporciona aquest factor, però, especialment per contrast amb els segles XI i XII, serveix per a orientar sobre la tendència evolutiva del fenomen. Així, es constata que entre els dos períodes hi ha hagut un capgirament en la forma dominant com a marca de tercera persona: hem passat d'una majoria de textos amb - a com a única solució (documents 2, 4, 5 , 6, 8, 9 i Io, enfront de 3, II i I $2 \mathrm{amb}-e$ ) a una majoria de textos amb - e com a solució exclusiva (documents I5, I6, I8, 22, 23, 24, 25, 26, 27, 29 i 30, enfront de I4, I9, 20 i 2I amb-a), com mostra la taula 2I.

Taula 2I. Classificació dels documents del corpus segons si s'hi empra només la variant - $a$, només la variant $-e$ o bé si hi alternen totes dues; s'hi constata el canvi de tendència entre els segles XI i XII $(\mathrm{amb}$ predomini de $-a)$ i el segle XIII (amb predomini de $-e$ )

\begin{tabular}{|r|l|l|c|c|}
\hline \multirow{2}{*}{ Doc. } & \multirow{2}{*}{ Datació } & \multicolumn{3}{|c|}{ Terminació de tercera persona } \\
\cline { 3 - 5 } & & Només $-a$ & Alternança $-a /-e$ & Només $-e$ \\
\hline 1 & $1036-1079$ & & Disputació referent... & \\
\hline 2 & $1043-1098$ & Jurament feudal 2 & & \\
\hline 3 & $1043-1098$ & & & Acords feudals 1-1 \\
\hline 4 & $1043-1098$ & Acords feudals 1-2 & & \\
\hline
\end{tabular}




\begin{tabular}{|r|l|l|l|l|}
\hline 5 & mitjan XI & Acords feudals 2-3 & & \\
\hline 6 & $1047-1098$ & Jurament feudal de... & & \\
\hline 7 & $1080-1095$ & & Greuges de Guitard... & \\
\hline 8 & $1094-1110$ & Acords feudals 3-5 & & \\
\hline 9 & 1117 & Acords feudals 3-6 & & \\
\hline 10 & $1 \mathrm{a}$ m. XII & Llibre dels judicis 1 & & \\
\hline 11 & XII & & & Greuges dels homes de... \\
\hline 12 & XII & & & Greuges dels homes... \\
\hline 13 & 1204 & & Homilies d'Organyà & \\
\hline 14 & 1211 & Rendició del castell de... & & \\
\hline 15 & 1241 & & & Donació d'oliverars... \\
\hline 16 & 1242 & & Controvèrsies... 1 & Queixes de l'església... \\
\hline 17 & 1243 & & & Controvèrsies... 2 \\
\hline 18 & $1243-1250$ & & & \\
\hline 19 & 1244 & Lletres en català... 1 & & \\
\hline 20 & 1248 & Donació de terres... & & Cartes al bisbe... 2 \\
\hline 21 & $1250-1255$ & Disputació entre... & & La venda del castell... \\
\hline 22 & $1230-1255$ & & & Lletres en català... 2-IV \\
\hline 23 & c. 1251 & & & Lletres en català... 2-VI \\
\hline 24 & $1257-1269$ & & & Lletres en català... 3-VII \\
\hline 25 & $1257-1269$ & & Lletres en català... 3-VIII \\
\hline 26 & $1257-1269$ & & Lletres en català... 3-XII \\
\hline 27 & $1257-1269$ & & & Lletres en català... 3-XIII \\
\hline 28 & 1259 & & & \\
\hline 29 & $1257-1269$ & & & \\
\hline 30 & 1288 & & & \\
\hline
\end{tabular}

De fet, els textos en què es troba exclusivament la variant - $a$ acaben cap a mitjan segle XIII (el més tardà és el doc. 2I, datat entre I250 i I255) i, si hi afegim els que alternen - $a \mathrm{i}-e$, la data tampoc no s'endarrereix gaire (baixa a I259). D'altra banda, poc abans de la meitat del segle XiII, comencen a sorgir documents que només presenten la variant de tercera persona amb - e tot i contenir formes de present de subjuntiu (doc. I6 -el més antic, de I242-, I8, 22, 23, 24, 27, 29 i 30). Ho remarquem perquè, als segles precedents, no havíem trobat cap forma de $3 \mathrm{PS}$ amb -e (les més endarrerides apareixen a les Homilies d'Organyà, de I204, i només afecten el submodel incoatiu, com hem vist). Pel que fa a la llengua escrita, doncs, sembla que podríem establir una frontissa cap a mitjan segle XIII, que deixaria enrere la fase d'expansió de la variant -e i obriria l'entrada a una etapa de canvi força consolidat. 
Mar Massanell i Messalles

Sincretisme i canvi morfològic: evolució de la terminació verbal en -AT en català

\section{CONCLUSIONS}

Ens hem centrat en l'evolució en català de la terminació verbal àtona llatina -AT, que es troba en els ètims de les formes verbals de tercera persona del present d'indicatiu de la primera conjugació (CANTAT > canta), del present de subjuntiu de les conjugacions no primeres (BATTAT > bata) i de l'imperfet d'indicatiu (CANTABAT > cantava, BATTEBAT $>$ batia) i del condicional (CANTARE HABEBAT > cantaria, BATTUERE HABEBAT > batria) de totes les conjugacions. L'interès per aquesta terminació parteix del fet que actualment el català nord-occidental no tortosí i una gran part del valencià septentrional presenten solucions del tipus cante, cantave, cantarie, que s'aparten del resultat general amb - $a$ final, les quals es documenten des dels primers testimonis escrits parcialment o totalment en llengua catalana (segle XI).

$S$ 'ha proposat un origen purament fonètic per a aquesta terminació - $e$, que en justifica el sorgiment suposant una pèrdua tardana de la -T final llatina en el català occidental naixent, circumstància que faria que operés el tancament de A final travada (CANTAT > cantet $>$ cante). Tanmateix, aquest tancament, ben establert en el pas de -AS a -es (ROSAS > roses, CANTAS > cantes) i de -ANT a -en (CANTANT > canten), no sembla que estigui lliure d'incerteses en altres contextos. Això ens ha portat a plantejar-nos la possibilitat d'un resultat inicial unitari amb $-a$ per a tot el català, mudat en - $e$ en el nord-occidental naixent per raons de caire morfològic $i$, més concretament, pel rebuig al sincretisme entre la primera persona i la tercera, que és observable tant en els paradigmes nord-occidentals més consolidats (canto / cante, cantava / cantave, cantaré / cantarà, cantaria / cantarie, [que] canta I [que] canto, [que] cantessa / [que] cantés) com en les innovacions que incorpora en l'actual procés de canvi a què es troba sotmès per la pressió de l'estàndard central ( $3 \mathrm{PS}$ canto $\rightarrow$ canti, però es manté IPS canta).

Hem bastit la hipòtesi de l'origen morfològic de la terminació -e de tercera persona recorrent a alguns dels principis de la morfologia natural. Jeràrquicament hem situat en primer lloc el principi de transparència, que afavoreix que cada forma realitzi una única funció, i que sembla el pilar fonamental del sistema morfològic nord-occidental. Aquest hauria estat el detonant de la transformació de cantava cap a cantave a la tercera persona de l'imperfet d'indicatiu, que és el temps on la hipòtesi situa l'inici del canvi, atès que és el menys marcat i més freqüent dels tres que presenten sincretisme entre la primera persona i la tercera (II, C i PS). Aquesta transformació, a més, es podia considerar un guany en uniformitat: dels dos al-lomorfs d'imperfet d'indicatiu, s'expandia ve (cantaves, cantave, cantaven) i es restringia va, que quedava identificat amb la primera persona (cantava). Per tant, també es reforçava la iconicitat estructural, que afavoreix els paradigmes en què les formes més marcades des del punt 
de vista funcional ho són també des del punt de vista formal: la primera persona, més marcada, es quedava amb el segment restringit $v a$, mentre que la tercera adoptava el segment genèric ve i passava a distingir-se de la sisena (o tercera del plural) només per l'absència de la marca - $n$; es produïa, en darrer terme, un ascens en la jerarquia d'iconicitat. El canvi en el condicional reportava aquests mateixos avantatges i, per això, també hi era esperable l'expansió de la terminació - e de tercera persona, seguint els passos de l'imperfet d'indicatiu, temps més freqüent $\mathrm{i}$, per tant, més propens a les innovacions.

El present d'indicatiu dels verbs de la primera conjugació, que no patia sincretisme de persona (jo cant / ell canta), havia de transformar-se per unes altres raons. La mutació de canta en cante respon al principi de congruència del sistema, ja que n'incrementa la sistematicitat d'acord amb els paràmetres morfològics del nord-occidental, en generalitzar la terminació - $e$ transversalment a diversos paradigmes (cantave $\rightarrow$ cantarie $\rightarrow$ cante). A més, també millora la uniformitat intraparadigmàtica, perquè deixa un únic al-lomorf a totes les formes de present d'indicatiu que tenen vocal àtona: cantes, canta, canten $\rightarrow$ cantes, cante, canten. Malgrat l'absència de sincretisme, doncs, la transformació en el present d'indicatiu havia de seguir la que s'havia originat en l'imperfet d'indicatiu i expandit al condicional.

Finalment, el darrer temps a veure-se'n afectat havia de ser el present de subjuntiu. Malgrat que presentava sincretisme de persona ([que jo] bata / [que ell] bata), i el canvi de terminació a $3 \mathrm{PS}$ era un guany en transparència ([que jo] bata / [que ell] bate), la hipòtesi de l'origen morfològic de la terminació - e el situa a la darrera baula de la cadena $(3 \mathrm{II} \rightarrow 3 \mathrm{C} \rightarrow 3 \mathrm{PI} \rightarrow 3 \mathrm{PS}$ ), perquè la coincidència formal s'accepta millor en el context d'un mode marcat, com és el subjuntiu.

Formulada la hipòtesi, calia anar als textos per a veure si aportaven dades que hi donessin suport documental —o que la refutessin. Aquestes dades només podien provenir dels textos més arcaics conservats: en el present treball no ens interessava constatar la vitalitat de la terminació - e al llarg de la història, ni resseguir-ne l'avenç geogràfic, ni investigar a partir de quan, o fins a quin punt, es dissimulava pel fet de ser considerada una forma "pagesívola» - per utilitzar un qualificatiu extret de les Regles, que la condemnen obertament—,${ }^{31}$ sinó que teníem l'objectiu de resseguir-ne els primers passos en els textos de la societat feudal. Per això, hem recorregut al Corpus

3I. «[I65] més avant són de evitar sobretot tots vocables los quals manifestament se coneix són de payssos de Catalunya o Valèntia diversos dels catalans, com és: [...] [I70] anave per dir anava [...] [I73] no res menys, entre persones de bon ingeni e experièntia, facilment se coneix dits vocables ésser de Empurdà, o de Urgell, o de Mallorques, o de Xàtiva, o de les muntanyes o pagesívols, dels quals no acustumen usar los cortesans ne elegants parladors e trobadors» (Badia i Margarit I999: II9-I20).

Caplletra 61 (Tardor, 2016), pp. 165-209 
Informatitzat del Català Antic i n'hem extret els documents dels segles XI, XII i XIII corresponents al català nord-occidental — bàsicament, procedents dels antics comtats d'Urgell i de Pallars.

La visió global que es desprèn del buidatge de les formes de tercera persona del corpus és compatible amb la hipòtesi formulada de l'origen morfològic de la terminació -e, que es veu més afavorida per les dades que no pas la hipòtesi d'un origen purament fonètic. Si tot es degués a una evolució fonètica regular del tipus -AT >-et $>-e$, la presència de la grafia - $e$ hauria de ser força sistemàtica $i$, sobretot, equiparable en tots els temps verbals afectats, circumstància que no es produeix. D'altra banda, tot i que la major part dels textos del corpus són força breus i no contenen gaire formes, s'hi observen dues sèries de correlacions entre els diversos temps pel que fa a la presència de la terminació - $a$ (expressables a través de les implicacions següents: si 3 II té - $a$, llavors ${ }_{3} \mathrm{C}$, 3 PI i 3 PS tenen $-a$; si 3 C té $-a$, llavors ${ }_{3} \mathrm{PI}$ i 3 PS tenen $-a$; si 3 PI té $-a$, llavors ${ }_{3} \mathrm{PS}$ té $-a$ ) i de la terminació - $e$ (expressables a través d'aquestes altres implicacions: si ${ }_{3} \mathrm{PS}$ té $-e$, llavors $3 \mathrm{II},{ }_{3} \mathrm{C}$ i $3 \mathrm{PI}$ tenen $-e$; si ${ }_{3} \mathrm{PI}$ té -e, llavors ${ }_{3} \mathrm{II}$ i ${ }_{3} \mathrm{C}$ tenen $-e$; si $3 \mathrm{C}$ té -e, llavors $3 \mathrm{II}$ té -e), ambdues compatibles amb la seqüència d'expansió de la variant innovadora formulada en la hipòtesi ( $3 \mathrm{II} \rightarrow 3 \mathrm{C} \rightarrow 3 \mathrm{PI} \rightarrow 3 \mathrm{PS}$ ).

Però les dades més significatives les hem obtingut del buidatge d'una obra singular continguda en el corpus, d'extensió molt superior a la resta de documents: les Homilies d'Organyà. La distribució de la variant - $e$ en aquest homiliari (62\% en l'imperfet d'indicatiu — que s'eleva a $75 \%$ a la primera conjugació i baixa a $55 \%$ a les altres-, enfront de I4\% en el condicional, IO\% en el present d'indicatiu i I $3 \%$ en el present de subjuntiu — però amb casos només en el submodel incoatiu) suggereix que el canvi cap a la terminació - e s'hauria iniciat, efectivament, en l'imperfet d'indicatiu, i en concret a la primera conjugació ( $j o$ cantava, ell cantava $\rightarrow$ jo cantava, ell cantave), la que aplega més verbs i l'única productiva juntament amb el submodel incoatiu, i després s'hauria estès a l'imperfet d'indicatiu de les conjugacions no primeres (jo batia, ell batia $\rightarrow$ jo batia, ell batie), amb un avanç molt ràpid en el cas de l'imperfet irregular ere, afavorit per metafonia.

A partir d'aquí, el model antisincrètic s'hauria expandit al condicional (jocantaria, ell cantaria $\rightarrow$ jo cantaria, ell cantarie i jo batria, ell batria $\rightarrow$ jo batria, ell batrie), un temps menys freqüent amb el mateix conflicte d'opacitat entre la primera persona i la tercera. La consolidació de la -e de tercera persona a l'imperfet d'indicatiu, i l'expansió cap al condicional, hauria afectat el present d'indicatiu de l'única conjugació amb desinència vocàlica a la tercera persona, i la tendència a l'homogeneïtat paradigmàtica n'hauria afavorit la transformació (jo cant, ell canta $\rightarrow$ jo cant, ell cante), atès que la forma amb - e és més congruent en el sistema (canta, cantave, cantarie $\rightarrow$ cante, 
cantave, cantarie) i incrementa la uniformitat intraparadigmàtica per la reducció de dos al.lomorfs a un (cantes, canta, canten $\rightarrow$ cantes, cante, canten).

En darrer terme, la terminació - $e$ penetraria en el present de subjuntiu de les conjugacions no primeres, temps menys propens al canvi, atès que les coincidències formals se suporten millor en contextos marcats. A partir del submodel incoatiu, el segment -esc- del qual, amb e tònica, afavoria la implantació del canvi per metafonia (seguesque), s'arribaria a la darrera de les transformacions: (que jo) bata, (que ell) bata $\rightarrow$ (que jo) bata, (que ell) bate, no recollida a les Homilies, però sí en textos posteriors del corpus, en el qual s'observa un increment remarcable de la presència de la variant - $e$, i de l'exclusivitat d'aquesta variant en molts textos, així que avança el segle XIII.

A manca de més documents del català occidental naixent, i més extensos, que forneixin més i millors dades a la qüestió, pensem que el buidatge del Corpus Informatitzat del Català Antic aporta, a la hipòtesi de l'origen morfològic de la terminació -e de tercera persona, un grau de suport documental que permet de tenir-la en consideració.

Mar Massanell i Messalles Universitat Autònoma de Barcelona mar.massanell@uab.cat ORCID oooo-0ooI-9288-5974

\section{REFERÈNCIES BIBLIOGRÀFIQUES}

Alcover, Antoni M. \& Francesc de B. Moll (1930-I962) Diccionari català-valenciàbalear $[D C V B]$, Palma, Moll.

Badia i Margarit, Antoni M. (I98I) Gramàtica històrica catalana, València, Tres i Quatre.

- (1999) Les Regles de esquivar vocables $i$ «la qüestió de la llengua», Barcelona, IEC. Coromines, Joan (197I) Lleures i converses d'un filoleg, Barcelona, Club Editor.

Creus, Imma (2002) «La morfologia verbal nord-occidental: dades per al tractament cronolectal de l'imperfet d'indicatiu", Estudis de llengua i literatura catalanes, XLV, Miscel.lània Joan Veny, I, pp. 33-66.

Dressler, Wolfgang U., Willi Mayerthaler et alii, eds. (1987) Leitmotifs in natural morphology, Amsterdam/Filadèlfia, John Benjamins.

Griera, Antoni (I9I7) «Les Homilies d'Organyà», Vida Cristiana, IV, 2I, pp. I32-I38; IV, 22, pp. I72-I78. 
Mar Massanell i Messalles

Sincretisme i canvi morfològic: evolució de la terminació verbal en -AT en català

Martí i Castell, Joan (1990) Gramàtica històrica. Problemes i mètodes, València, Universitat de València.

- (20I4) Aportacions a l'estudi de la filologia i la lingüistica catalanes, Barcelona, PAM.

Massanell i Messalles, Mar (20II) Permeabilitat del català nord-occidental a l'estàndard mediàtic i educatiu: el cas de l'Alt Urgell, Barcelona, IEC.

- (2012) «Feve temps que no diva tants verbs!' Manteniment i transformació de paradigmes verbals en el català nord-occidental del tombant de segle, Barcelona, PAM.

Massanell, Mar \& Gemma Palà (en premsa) "Que ho faça jo?! Que ho faci ell! Evolució del present de subjuntiu en el nord-occidental actual», Zeitschrift für Katalanistik.

Moll, Francesc de B. (199I) Gramàtica històrica catalana, València, PUV.

Moran i Ocerinjauregui, Josep (1990) Les Homilies de Tortosa, Barcelona, Curial/ PAM.

- (1997) «La prédication ancienne en Catalogne. L'activité canoniale», dins La prédication en Pays d'Oc (XIIe - début XVe siècle), Tolosa de Llenguadoc, Privat, pp. 17-35. [«Cahiers de Fanjeaux», 32.]

Moran, Josep \& Joan Anton Rabella (200I) Primers textos de la llengua catalana [PTLC], Barcelona, Proa.

Pérez Saldanya, Manuel (1998) Del llatí al català. Morfosintaxi verbal històrica, València, Universitat de València.

Puig I TÀrrech, Armand (200I) Les Homilies d'Organyà: estructura i fonts, Barcelona, Barcino.

RAsico, Philip (1982) Estudis sobre la fonologia del català preliterari, Barcelona, Curial/ PAM.

- (2006) El català antic [ECA], Girona, CCG Edicions.

Rossinyol, Andreu \& Amadeu-J. Soberanas, eds. (2004) Homilies d'Organyà. Edició trilingüe amb el facsímil del manuscrit, Barcelona, Barcino.

Russell-Gebbett, Paul (1965) Mediaeval Catalan Linguistic Texts [MCLT], Oxford, The Dolphin Book.

Soberanas, Amadeu-J., Andreu Rossinyol \& Armand Puig, eds. (200I) Homilies d'Organyà, Barcelona, Barcino.

Torruella, Joan, Manuel Pérez Saldanya \& Josep Martines, dirs., Corpus Informatitzat del Català Antic (CICA) [En línia: <www.cica.cat>.]

VäÄNÄNEn, Veikko (1985) Introducción al latín vulgar, Madrid, Gredos.

VeNY, Joan (1993) Dialectologia filologica, Barcelona, Curial/PAM.

— (1998 [1978]). Els parlars catalans, Mallorca, Moll. [ı2a ed.] 
VenY, Joan \& Mar Massanell (2015) Dialectologia catalana. Aproximació pràctica als parlars catalans, Barcelona/Alacant/València, PiEUB/PUA/PUV.

WheELER, Max W. (1984) «La conjugació valenciana: geografia, diacronia i psicologia», dins Miscel-lània Sanchis Guarner, I. Estudis en memòria del professor Manuel Sanchis Guarner: Estudis de llengua i literatura catalanes, València, Universitat de València, pp. 409-419.

- (1993a) "On the hierarchy of naturalness principles in inflexional morphology», Journal of Linguistics, 29, pp. 95-III.

- (2007 [1993b]) «El canvi flexional: els verbs en el català nord-occidental», dins Morfologia i fonologia catalana i romànica: estudis diacrònics, Alacant/Barcelona, IIFV/PAM, pp. IOI-I38. [Traducció de «Changing inflection: verbs in North West Catalan", dins David Mackenzie \& Ian Michael (eds.), Hispanic Linguistic Studies in honour of F. W. Hodcroft, Oxford, Dolphin, 1993, pp. 171-206.]

Wurzel, Wolfgang U. (1989) Inflectional Morphology and Naturalness, Dordrecht/ Boston/Londres, Kluwer Academic Publishers. 